OPEN ACCESS

Edited by:

Ákos Pogány,

Eötvös Loránd University, Hungary

Reviewed by:

María Del Carmen Viera,

Universidad de la República, Uruguay Hilton F. Japyassú,

Federal University of Bahia, Brazil

*Correspondence:

Theodora Fuss

theodora.fuss@uni-siegen.de

Specialty section:

This article was submitted to Behavioral and Evolutionary Ecology,

a section of the journal

Frontiers in Ecology and Evolution

Received: 29 July 2021

Accepted: 21 October 2021

Published: 11 November 2021

Citation:

Fuss T (2021) Mate Choice, Sex Roles and Sexual Cognition: Neuronal Prerequisites Supporting Cognitive Mate Choice.

Front. Ecol. Evol. 9:749499. doi: 10.3389/fevo.2021.749499

\section{Mate Choice, Sex Roles and Sexual Cognition: Neuronal Prerequisites Supporting Cognitive Mate Choice}

\author{
Theodora Fuss* \\ Department of Chemistry - Biology, Institute of Biology, University of Siegen, Siegen, Germany
}

Across taxa, mate choice is a highly selective process involving both intra- and intersexual selection processes aiming to pass on one's genes, making mate choice a pivotal tool of sexual selection. Individuals adapt mate choice behavior dynamically in response to environmental and social changes. These changes are perceived sensorily and integrated on a neuronal level, which ultimately leads to an adequate behavioral response. Along with perception and prior to an appropriate behavioral response, the choosing sex has (1) to recognize and discriminate between the prospective mates and (2) to be able to assess and compare their performance in order to make an informed decision. To do so, cognitive processes allow for the simultaneous processing of multiple information from the (in-) animate environment as well as from a variety of both sexual and social (but non-sexual) conspecific cues. Although many behavioral aspects of cognition on one side and of mate choice displays on the other are well understood, the interplay of neuronal mechanisms governing both determinants, i.e., governing cognitive mate choice have been described only vaguely. This review aimed to throw a spotlight on neuronal prerequisites, networks and processes supporting the interaction between mate choice, sex roles and sexual cognition, hence, supporting cognitive mate choice. How does neuronal activity differ between males and females regarding social cognition? Does sex or the respective sex role within the prevailing mating system mirror at a neuronal level? How does cognitive competence affect mate choice? Conversely, how does mate choice affect the cognitive abilities of both sexes? Benefitting from studies using different neuroanatomical techniques such as neuronal activity markers, differential coexpression or candidate gene analyses, modulatory effects of neurotransmitters and hormones, or imaging techniques such as $\mathrm{fMRI}$, there is ample evidence pointing to a reflection of sex and the respective sex role at the neuronal level, at least in individual brain regions. Moreover, this review aims to summarize evidence for cognitive abilities influencing mate choice and vice versa. At the same time, new questions arise centering the complex relationship between neurobiology, cognition and mate choice, which we will perhaps be able to answer with new experimental techniques.

Keywords: sex role, plasticity, immediate early gene (IEG), neurotransmitters and hormones, personality, neural integration, sex difference, brain size 


\section{INTRODUCTION}

An individual perceives, acquires and stores private and public (social) information available in its environment, responds to it, and, finally, draws an appropriate decision. Various sensory and cognitive processes associate, integrate and prioritize a wide variety of (social and/or non-social) environmental stimuli within an individual's perceptual range, thereby controlling important behavioral responses and life history decisions. For instance, odor perception is an important determinant of different aspects of zebra finch social behavior (e.g., kin/parent recognition: Krause et al., 2012; Golüke et al., 2016; Caspers et al., 2017; mate choice: Caspers et al., 2015) and is mirrored sexspecifically in brain activity (Golüke et al., 2019). Daylight length is one of the factors that migratory birds use to decide when to start their fall or spring migration. Various factors determine which information to prioritize for a decision: how does an individual perceive the information? Is it capable of drawing an (proximate) association between the stimulus, the likely consequences, and its own fitness benefits? Has natural and/or sexual selection adequately shaped an individual's abilities to assess the costs and benefits of appropriate versus inappropriate decisions? Does it aptly possess the cognitive skills for any of these complex learning, memory, and evaluation processes? Hence, depending on the context, different forms of learning prevail. These include rapid, very robust and irreversible learning processes such as imprinting shortly after birth and slower, more complex but flexible processes such as trial-and-error learning (e.g., access to a nutritious food source). For instance, in some birds, horses, goats, or bovids, newborn young have to be able to keep up with their parents shortly after birth. To them it is crucial to grasp this need quickly, because slow learners may not be given a second chance (e.g., Ewer, 1956; Hess, 1959, 1964; Immelmann, 1975; Salva et al., 2015; Mayer et al., 2016). On the other hand, Meerkat adults teach their young in several successive steps and over a period of several weeks how to handle highly venomous scorpions as a particularly tasty and nutritious food source (Thornton and McAuliffe, 2006; Thornton, 2008; Thornton and Raihani, 2010). For non-learners, any contact with live venomous prey may be the last.

'Cognition' is commonly described in terms of the neuronal processes that are principally engaged in the reception, processing, storage, and retrieval of information (Shettleworth, 2001; Dukas, 2004). Yet the capacity to learn and to draw associations between different stimuli is another important determinant of cognitive ability (Giurfa et al., 2001). More specifically, 'cognition' as all processes that involve thinking,

Abbreviations: $A p o D$, apolipoprotein $\mathrm{D} ; B D N F$, brain-derived neurotrophic factor; CMM, caudomedial mesopallium; Dm, Dl, medial and lateral telencephalon; egr-1, early growth response gene 1; fMRI, functional magnetic resonance imaging; GnRH, gonadotropin releasing hormone; HV, ventral zone of periventricular hypothalamus; IEG, immediate early gene (e.g., c-fos, egr-1); $\mathrm{LNH}$, lateral neo- and hyperstriatum; $\mathrm{MNH}$, medial neo- and hyperstriatum; NCC, caudocentral nidopallium; NCM, caudomedial nidopallium; NI, Nucleus incertus; POA, preoptic area; SBN, social behavior network; SDMN, social decision-making network; SPG, synaptic plasticity gene; VTA, ventral tegmental area; Vs, supracommissural nucleus of the ventral telencephalon; $\mathrm{Vv}$, ventral zone of the ventral telencephalon. reasoning, perceiving, imagining, and remembering to constitute concepts that "can be systematically recombined with each other", are "stimulus-independent" and, thus, can be transferred to new contexts (Bayne et al., 2019). For instance, is an animal able to recognize familiar individuals in a group of conspecifics regardless of context? Is it able to distinguish and categorize these familiar individuals as potentially having different consequences for itself (e.g., companion, rival, potential mate)? Is its response to a particular individual characterized by its ability to remember previous interactions?

Moreno and Mossio (2015) added the idea of "neurodynamic autonomy" to the discussion, which suggests that once the neurodynamic organization has reached a certain level of autonomy and is subject to a set of higher-level monitoring and integration mechanisms, the self-organizing dynamic character develops. Drawing on their notion of "neurodynamic autonomy", interactive experiences such as affective interactions contribute significantly to the development and shaping of socio-cognitive mechanisms. Accordingly, cognition also involves the effective control of attention and emotions, which drives the need to perceive, interpret, and respond to the emotions (and, thus, behavior) of other organisms. Thereby, "neurodynamic autonomy" contributes to communicative, competitive, and cooperative aspects of social behavior (e.g., inter- and intraspecific, inter- and intrasexual) (Moreno and Mossio, 2015).

In many species across different taxa, mate choice is a highly selective process that involves both, intra- as well as intersexual selection processes aiming to pass on one's genes, making the underlying behavioral mechanisms a significant factor in sexual selection. Although many aspects of mate choice behavior, coloration and ornamentation are well understood, the underlying neuronal mechanisms of female mate choice have been fairly neglected. In vertebrates, this sexual behavior is likely to be guided and adapted by an interplay of the same neuronal circuits as social, non-sexual behavior (e.g., territorial aggression, parental care). Mate choice behavior is modified permanently in response to ecological and social changes, which are initially perceived sensorily, undergo neuronal analysis and interpretation in a subsequent step, and, finally, elicit to an adequate behavioral response (compare DeAngelis and Hofmann, 2020 for review). Cognitive processes allow the synchronous processing of multiple sources of information from the (in-) animate environment and from a variety of social cues. However, the exact neuronal mechanism, the cognitive prerequisites and effectiveness inducing the display recipient to finally select a particular courting partner are not yet fully understood. Across all vertebrate taxa, the prevalence of more or less well-developed cognitive capabilities is closely linked to brain development and, to some extent, to overall brain size (brain to body mass ratio, encephalization quotient) or the prominence of single brain regions such as the telencephalon. Moreover, connectivity and the number of neurons in a given brain region or neuronal network are considered appropriate determinants of cognitive performance in an individual, sex, or species (Iwaniuk, 2017). Information an individual receives from the environment can trigger complex neurophysiological mechanisms such as neuronal signal transduction, structural and 
synaptic modifications, or molecular regulations, ranging from altered gene expression to epigenetic changes that ultimately lead to changes in brain function, phenotypic variations, and adaptive behaviors (Maruska et al., 2014).

However, the development of higher cognitive skills provides true selective benefits only if they cover the (fitness) costs. At a behavioral level, costs may involve time-consuming trialand-error learning processes until a behavioral pattern is appropriately adapted. Both (social) imprinting and complex (social) learning processes ensure that the respective brain regions involved are cross-linked. Different nuclei are recruited to support different aspects of learning, depending on the dominant learning process in progress. The same applies to social cognition, i.e., cognitive skills in sexual and non-sexual contexts and interactions, respectively (e.g., Bolhuis and Honey, 1998; Reader, 2003; Di Giorgio et al., 2017; Joiner et al., 2017). To give an example, the cognitive traits of innovativeness and problem-solving skills are considered particularly attractive to potential mates. They were found to be correlated positively to the individual learning ability and to the size of the corresponding associative brain regions in birds (hyperstriatum ventrale, neostriatum) and primates (neocortex, striatum) (Reader, 2003). At the neuronal level, the development and maintenance of the adequate neuronal circuits demand an increased energy supply. Many neuronal mechanisms, molecular pathways, and neuronal networks known to mediate sexual and social behavior and, in particular, to be involved in social cognition in vertebrates appear to be highly conserved evolutionarily across taxa. Altogether, they appear to govern cognition in mate preference and, therefore, to modulate important aspects of sex-specific mating behavior (Weitekamp and Hofmann, 2014). Although a number of exciting examples of social cognition have been observed in various species at a behavioral level, there is still astonishingly limited understanding of the underlying neuronal prerequisites and the neuronal plasticity of adaptive and contextdependent sexual behaviors in different vertebrate groups. More specifically, a surprisingly high level of uncertainty remains about neuronal mechanisms involved particularly in the process of mate choice, which is why this review covers social (nonsexual) cognitive issues, but aims to highlight the context of mate choice whenever available. Moreover, differently pronounced sexual dimorphisms in brain structure, brain size, and in various neuronal mechanisms have been found in different species. However, how does the neuronal activity of males and females differ with respect to sexual cognition? Hence, is the sex and/or the respective sex role within the prevalent mating system mirrored at the neuronal level? How does cognitive competence affect mate choice and, conversely, how does mate choice affect cognitive competence of both sexes?

\section{SEX-DRIVEN BEHAVIOR IS REFLECTED IN THE BRAIN}

Genes, neuronal prerequisites, and their ensuing processes and mechanisms are shaped, modified, and adapted throughout an individual's life, depending on the environmental conditions (e.g., con- and heterospecifics, predation, and food availability), its life and learning experiences, sexual status, social rank within its group etc., to name just a few examples. The same applies in reverse, implying a reciprocal interaction between all the aforementioned determinants.

Different social contexts showed different covariance patterns of 11 genes and their associated behavior (Ramsey et al., 2012). The important role of plasticity in courtship behavior was also evident upon blocking NMDA ( $N$-methyl-D-aspartate) receptors, which play a critical role in learning-induced synaptic plasticity, while significantly affecting female preference behavior (Ramsey et al., 2014). Learning-induced synaptic plasticity can be observed also in various vertebrate taxa in various social (e.g., Sockman, 2007; Wang et al., 2014; Cummings, 2015; Cummings and Ramsey, 2015; Delclos et al., 2020) contexts and (non-social) learning tasks (e.g., Alcock, 2001; Bozon et al., 2002; Davis et al., 2003; Fuss and Schluessel, 2018).

There are several facets of reproductive behavior in most sexually reproducing species that differ between males and females. The term 'sex' in the context of this review refers to biologically defined and genetically acquired differences between males and females that are evident in their physiology and reproductive abilities or potentials. Also included are biological factors such as internal or external sex organs, gonadal differentiation (testis and ovary), gamete production, sex hormones (e.g., androgens, estrogens, and progestogens), or sex chromosomes (e.g., XY male, XX female in most mammals, or $\mathrm{ZZ}$ male, ZW female in birds) that are considered to determine a sex. For instance, sex chromosomes and, particularly, sex chromosome genes (X- or Y-linked and Z- or W-linked genes) are contributory to sex differences in the brain of both mammals and birds ("neuronal sex chromosome genotype", Arnold, 2004; Scholz et al., 2006; Jazin and Cahill, 2010; Maekawa et al., 2014; Loke et al., 2015). Several studies propose genetic and nongenetic factors, such as social incentives or other environmental influences, may interact (e.g., Ristori et al., 2020). Environmental influences can be highly complex and may be driving forces for plastic changes in brain morphology (Maguire et al., 2000; Driemeyer et al., 2008; Quallo et al., 2009; Scholz et al., 2009; Blumenfeld-Katzir et al., 2011; Lerch et al., 2011; Fong et al., 2019). Consequently, sex roles (or their reversal), ecology, or sex differences respond plastically to environmental drivers with regard to their effects on female or male reproductive fitness (e.g., Amundsen, 2018; Hare and Simmons, 2020, 2021). In this context, sex roles are intuitively associated with both stereotypically female and male sexual behaviors, which comprise biological phenomena such as, for instance, mating competition, mate choice, or nature, extent and/or duration of parental care (e.g., Ah-King and Ahnesjö, 2013). The nature and the behavioral expression of sex differences vary greatly between species, populations, or cultures. Consequently, sex roles refer to socially encoded behaviors, traits, and/or attributes associated with being (genetically) male or female.

Several neuronal processes supposedly interact with each other to coordinate sensory perception, memory, cognitive and emotional responsiveness in a complex neuronal network to allow for a coherent perception and decision-making framework 
(e.g., Skov and Nadal, 2020). For instance, based on wholebrain functional maps, socially deprived zebrafish were observed to experience significantly weaker activity in brain regions associated with social behavior and social stimulus processing, but significantly higher activity in regions involved in anxiety or stress when back in contact with zebrafish raised in social populations. These early isolation impairments were reversed by modulating serotonin levels in formerly isolated fish (Tunbak et al., 2020). When analyzing swimming movements in a variety of different contexts ranging from hunting and predator avoidance to social interactions, socially deprived larvae where observed to exhibit significantly more social avoidance responses compared to their group-raised conspecifics (Marques et al., 2018). Studies in human and non-human primates identified a key moderating involvement of the amygdala, the ventromedial frontal cortices and the right somatosensory cortex, which are crucial to view conspecifics, retrieve knowledge, or trigger an appropriate behavior (i.e., perceptual representation of socially relevant stimuli) (Adolphs, 1999). Together with instinctive knowledge, perception and processing of socially relevant information (as examples of acquired knowledge) appear to promote social cognition, with a strong dependence on the own sex role (Geary, 2002; Proverbio, 2017, 2021; Pearce et al., 2019). Sexual and social challenges and (unpredictable) ecological events initiate adaptive physiological and behavioral responses that may provide an animal with either a selective advantage or disadvantage.

\section{Cognitive Sex Differences and Social Information Trigger Multiple Regulatory Neuronal Processes}

Social information triggers various neuromodulatory mechanisms. These mechanisms contribute to the adaptive plasticity of social support (e.g., Snell-Rood and Snell-Rood, 2020). In addition, they enable adaptive plasticity in social learning including, but not limited to copying mate choice (e.g., Gouda-Vossos et al., 2018; Zhuang et al., 2021), vocal learning, tutoring, and preference in early sensory periods (e.g., Hauber et al., 2021), dealing with nutritional stress (and its consequences, e.g., on offspring growth, brain development, and learning; e.g., Nowicki et al., 2002), or disgust (e.g., to enable pathogen and/or toxin avoidance; Kavaliers et al., 2019 for a review). Likewise, acquiring sexual information triggers numerous regulatory neuronal processes to allow social individuals to assess and respond quickly and appropriately to a potential mate's courtship display, but taking into account their own social and/or sexual role, motivation, and cognitive abilities (Kavaliers and Choleris, 2017). Accordingly, a central focus of neuroscience research is to elucidate (a) how mate choice processes emerge and are managed in the brain, (b) how the brain perceives and integrates sexual interaction and, subsequently, (c) replies to changes in the sexual context by designing a well-adapted behavioral response. In many conventional mating systems, females provide a greater investment into the offspring than males. Although there are species in which males participate in brood care or even provide it completely, it is initially to the females to expend the greater amount of energy for gamete production. Therefore, females frequently perform the pivotal role of choosing between competing males. There is a rich body of studies examining many behavioral details of the female decision-making process. Across taxa, there is evidence that neuronal substrates and networks supporting competitive malemale aggression, temporal or lifelong pair bonding, or (shared) parental brood care are presumably also engaged in (female) mate choice. Supporting neuronal prerequisites include, for instance, the Nucleus accumbens, the amygdala, the preoptic area (POA), or a number of cortical areas (DeAngelis and Hofmann, 2020). In this context, it is likely that these circuits are modulated over a lifetime, and in response to an individual's (speciesspecific and cross-species) social and ecological environment (e.g., predation pressure, food availability, and defense of territory). This so-called neuronal plasticity presumably serves as the basis for behavioral plasticity and vice versa. In the context of mate choice, the choosing sex (mostly the females) has to be equipped with an elaborate and adequate set of higher cognitive abilities in order to (a) discriminate between and (b) to classify all available information such as the prospective mates' social rank, body condition (e.g., body size and coloration), health condition (e.g., nutritional status, infections, and parasitism), personality traits (e.g., aggressiveness, boldness, explorativeness, sociality, and risk-taking), and problem-solving abilities (e.g., spatial orientation, finding new resources such as food or shelters).

\section{Sex Differences: Cognitive Processes}

Sex-specific differences in behavior, brain activity, and brain anatomy have been found repeatedly in a wide variety of animal species in virtually all major vertebrate taxa. Numerous studies have provided wide ranging evidence to map the cognitive processes involved in social competence in the vertebrate brain. There is increasing support of the idea that complex cognitive functions are associated with a general pattern of activation of multiple brain networks, rather than with individual brain regions (McIntosh, 2000; Sporns, 2010; Fuss and Schluessel, 2018). Cognitive sex dimorphisms at a behavioral level along with their prospective neuronal mirroring help to understand the neuronal integration of cognitively demanding mate-choice cues. However, despite years of research, we can still only vaguely imagine the concrete neuronal 'blueprint' or 'wiring scheme', its diversity and composition for an (in-) dependent mate choice of one and against the other conspecific (Phelps et al., 2006; DeAngelis and Hofmann, 2020). Basically, mating behavior as an example of a complex social, cognitive behavior is accompanied by a change in neuronal brain activity and, conversely, triggers corresponding neuronal adaptations in response to, for instance, courtship, comparison of different prospective mates, or recognition and choice of the 'perfect mate'. Complex neuronal gene expression (e.g., IEGs, emission of secondary, retro- or anterograde neurotransmitters etc.) is involved frequently in the integration of cognitive mate-choice cues in the respective brain regions, aiming to serve as an initial and rapid neuronal response and, consequently, to allow contextdepended behavioral adaptations. It triggers plastic adaptations in the neuronal circuits, the synaptic activity of the targeted 
neuronal network, its metabolic processes, or the recruitment of further transcriptional pathways (Robinson et al., 2008; Zayed et al., 2012; Whitney et al., 2014) responsible for controlling and consolidating the intended (socio-) cognitive behavior (Dragunow, 1996; Davis et al., 2003; Plath et al., 2006).

The nature of the task, i.e., which 'cognitive domain' is addressed (e.g., spatial learning or memory, color discrimination, and counting) also plays a vital role in cognitive processes. In an interesting review, Yagi and Galea (2019) summarized a number of early and recent studies reporting pronounced sex differences in the hippocampus of humans and rodents in the context of spatial orientation. In addition to different sex-specific strategies in coping with given orientation tasks, testosterone or ovarian hormones, respectively, play a crucial role and could, for instance, increase or attenuate the preference for a particular strategy. Since these different strategies are processed in different neuronal ways, these results also pointed to the involvement of different regions in the male and female brain in spatial navigation. Additionally, age- and environment-dependent sex-specific differences in hippocampal morphology, cell signaling, synaptic plasticity, and activity in performing memory tasks have been reported in numerous mammalian species including humans and rodents (compare Koss and Frick, 2016 for review). Likewise, sex-specific differences were found in the age-dependent altered neuronal gene activity in the hippocampus of different-aged zebra finches (Kosarussavadi et al., 2017). In analogy to the domain-specific cognitive involvement of different brain nuclei, different patterns of gene activity are also reflected in the respective recruitment of multiple neuronal circuits depending on a social context (O'Connell and Hofmann, 2011, 2012). Taking fish in various social contexts as an example, locally increased brain activity [indicated by increased $c$-fos, egr-1/Aptegr-1, brainderived neurotrophic factor (BDNF) IEG expression levels] has been revealed in brain areas associated with social behavior. These include, for instance, the anterior POA, the nuclei of the 'social behavior network' (SBN) within the basal forebrain and midbrain, or the dorsolateral telencephalon (dorsal, central, and lateral subdivisions) (Burmeister et al., 2005; Harvey-Girard et al., 2010; Wood et al., 2011; Maruska et al., 2013). For instance, sex-specific differences were found in the age-dependent altered gene activity of apolipoprotein $D(A p o D)$ and the immediate early gene egr-1 in the hippocampus of different-aged zebra finches when solving a spatial task in a four-arm maze. Males performed better than their female conspecifics of the same age, and younger birds learned slightly better than older ones. The latter effect was particularly evident when comparing females of different ages involved in memory events. Females showed also a higher egr-1 expression than their male counterparts. The same was observed with respect to $A p o D$ expression levels in young zebra finches, possibly indicating neurobiological compensation of older birds (Kosarussavadi et al., 2017). At the same time, there is the advantage of being able to respond rapidly and dynamically to new contexts and adjust decisions via novel, flexible connections between the brain regions involved ('functional reconfiguration of connectivity', Sporns, 2010). The involvement of neuronal prerequisites supporting cognitive mate choice also echoes the different sex roles in mate choice. In both sexes, the respective brain network takes the lead, whose nuclei mainly store the (sexual) information on a particular situation (domain-specific social encoding).

\section{Neuronal Integration of Different Stimuli in the Context of Mate Choice}

It is well accepted that at least two processes of intersexual selection developed in parallel and, to some extent, mutually dependent. On the one hand, the promoting sex (i.e., the 'display producer') will possibly develop unique courtship displays to appear more attractive to the choosing sex than competing rivals. On the other hand, it would only be worth to develop sophisticated courtship displays, if the choosing sex (i.e., the 'display recipient') was able to perceive the spectacle and to compare between the contenders. Hence, it depends on the particular role a sex is assigned to in its respective mating system (e.g., monogamy, polygamy, promiscuity, conservative or sex-reversed role models, among others). For instance, sexually dimorphic characteristics include the vocal repertoire, the soundgeneration, and the sound-perceiving morphology. Thresholds for the recognition of sounds, and the neuronal key domains involved in the processing contribute to our understanding and interpretation of a particular species' communication processes. Any display beyond the perceptive range of the (choosing) recipient will remain undetectable (e.g., invisible, odorless, and inaudible) (Rosenthal, 2017). The brain regions and neuronal networks involved in courtship and mate choice, as well as the neuronal integration of different stimuli (targeting wellstudied senses such as olfaction, vision, or audition) have been studied across taxa, for instance via altered gene expression as neuronal activity markers or via the modulatory effects of neurotransmitters and hormones.

To give an example, in mammals there is parallel processing of 'sexual odors' (e.g., pheromones) by the vomeronasal system (e.g., flehmen behavior, Takigami et al., 2000; Vedin et al., 2010; Smith et al., 2015) in contrast to 'asocial odors' (e.g., food), which are processed by the main olfactory system (Bressler and Baum, 1996; Døving and Trotier, 1998; Kondo et al., 2003). Immunohistochemical studies used IEGs followed by brain lesions to reveal potentially altered activity and involvement of different brain regions in female mice after smelling males of different sex status (intact, castrated). IEG findings suggested a preference for intact males in the POA or medial amygdala. Moreover, lesions of these regions suggested that they were not involved in odor discrimination per se, but rather in a coordinated adjustment of female choice behavior in mice and rats (Bressler and Baum, 1996; Kondo et al., 2003; Sakuma, 2008; DiBenedictis et al., 2012).

With respect to visual processing of mate choice information, synaptic plasticity genes (SPGs) have been identified in both the optic nerve (grin1, march8, BDNF, thoc6, cant1, and thap6) and telencephalon (inhba, neurod2, smarcc1, c-fos, egr2b, and thap6) of female guppies that differ in their expression patterns in view of differently colored males engaged in 10-min courtship displays (Bloch et al., 2018). These genes were flexibly coordinated by different transcription factors. Hence, they served as distinct 
"neuromolecular switches", inducing different neurogenomic conditions underlying mating decisions and social behaviors (Bloch et al., 2018). They observed a clear difference in SPG expression levels between females that showed a preference for specific males in contrast to their indifferent conspecifics, which allowed them to pinpoint a brain region devoted to sensory processing (optic tectum) and a brain region devoted to a decision-making purpose (telencephalon). Particularly the SPGs grin1 and glul are well known to play critical regulatory roles in fish learning and memory processes. Consequently, Bloch et al. (2021) applied differential coexpression analysis on grin1 and glul to unravel the supportive and dynamic neurogenomic network that is involved in mate choice in female guppies during different mating conditions (evaluation of attractive and unattractive males) and social contexts (familiar conspecific females). Depending on the context, a remarkable degree of neuronal network recoding was revealed in the choosing female brain in different social situations. Supplementary analyses suggested, depending on the social, that these changes particularly affected learning, memory and other cognitive functions. For instance, some neuronal networks were found to be exclusively active during mate choice, while others only started to operate during non-specific social interactions (Bloch et al., 2021). Across taxons, face recognition in human, macaque and sheep brains involves respective specialized and social domain-specific neuronal networks, which are recruited context-dependent (Kendrick and Baldwin, 1987; Kanwisher and Yovel, 2006; Tsao et al., 2006, 2008). Visually guided mate preferences resulting in an altered expression pattern of several neuronal processing genes in the central brain, optic nerves, and ommatidia have also been reported from invertebrates (e.g., Heliconius melpomene, Heliconius cydno; Rossi et al., 2020). Besides a social context, the 'mode' of visual perception used to perceive a courtship display (left eye, right eye, or both eyes) seems to play an important role in mate preference and, consequently, in mate choice. For instance, zebra finch males displayed more pronounced courtship behavior when only the right eye was available compared to only the left eye. Additionally, right-eyed as well as binocular males preferred females with distinct orange beaks over females with gray beaks, which was not observed in left-eyed males (Templeton et al., 2014). Thus, an altered gene expression of zenk and c-fos during early courtship, song production but also sexual imprinting appears to be closely associated with the ability to evaluate prospective mates, male attractiveness, and reproductive success in various brain regions [including the optic tectum, the caudomedial mesopallium (CMM), the lateral neo- and hyperstriatum (LNH), the medial neo- and hyperstriatum (MNH)] (Lieshoff et al., 2004; Avey et al., 2005; George et al., 2006).

Relating to auditory mate choice signals, using functional magnetic resonance imaging (fMRI), immediate early gene expression patterns (egr-1), along with behavioral tests, Van Ruijssevelt et al. (2018) discovered another brain region involved in social decision making, particularly in the context of mate choice. Hitherto, these tasks have largely been attributed to the well-known sensory integrative regions of the central nidopallium in the avian forebrain, which are known to be involved in executive functions, but also in the processing of other higher cognitive tasks such as the perception and evaluation of male courtship songs. In addition to the wellknown involvement of the central nidopallium, they were able to reveal increased activity in the caudocentral nidopallium (NCC), a brain region assigned to the evaluation of acoustic signals underlying mate choice. The CMM responded to male songs of comparable temporal-acoustic patterning. In female starlings (Sturnus vulgaris), for instance, their preference for long or short songs elicited increased activity in the CMM depending on their previous social experience with conspecifics and the prevailing environmental conditions (Sockman et al., 2002; Sockman, 2007; Sockman and Ball, 2009). In túngara frogs (Physalaemus pustulosus), hearing calls from their own or a closely related frog species induced a sex-insensitive response of the IEG egr-1 in the Nucleus olivaris superior, which is responsible for processing acoustic stimuli in the brainstem. At the same time, the male torus semicircularis (laminar nucleus) responded with an increased egr-1 expression to con- and heterospecific calls, while females responded only to conspecific calls (Hoke et al., 2008). Hence, a preselection of the stimuli to be integrated in the decision-making process in the telencephalon appears to depend on the sex and the sex role, respectively, aiming to decide more effectively between rivals (males) or potential mates (females) (Wilczynski and Ryan, 2010).

Conclusively, it is not only an individual's genotype playing an influential role in mate choice. Instead, genotype together with neuronal gene expression patterns that are presumably evolutionarily conserved across different vertebrate taxa, constitute the basis of a decision in favor of or against a potential mate.

\section{Neurotransmitters and Hormones}

Other contributing determinants of a sex-specific neuronal integration of cognitive mate choice cues include the modulatory effects of many neurotransmitters and hormones. Many of these pathways are thought to be evolutionary conserved and operate similarly in many vertebrate taxa. Various neurotransmitters (e.g., dopamine and serotonin), opioid peptides, (sex) steroid hormones (e.g., testosterone and estrogens), corticosteroids, neurosteroids, and neuropeptides (e.g., oxytocin or argininevasopressin) precisely modulate the interplay of different neuronal networks, including the mesolimbic reward system, the SBN, the social salience network and other brain regions involved in social and/or sexual recognition as well as learning in the contexts of mate choice (Choleris et al., 2009, 2012; O'Connell and Hofmann, 2011; Gabor et al., 2012; Goodson, 2013; Petrulis, 2013; Ervin et al., 2015; Dumais and Veenema, 2016; Ashley and Demas, 2017; but see Kavaliers and Choleris, 2017; Froemke and Young, 2021 for review). For instance, in adult and larval zebrafish, the neuro-endocrine system, namely the fish ortholog of oxytocin (i.e., isotocin or 'zebrafish oxytocin') and, possibly, the fish ortholog of mammalian vasopressin (i.e., vasotocin or 'zebrafish vasopressin') appeared to support their social behavior and social preference, but not anxiety-related behavior (Landin et al., 2020). In humans, sex hormones were observed to regulate sexual behavior, memory capabilities and, 
consequently, hippocampal neurogenesis (Choleris et al., 2018). In humans and non-human animals, oxytocin reinforces sex differences in mate choice, suggesting its release during courtship reinforces sex-dependent priorities in both attractiveness and mate choice initially and, thereafter, supports pair bonding (Xu et al., 2020; reviewed in Froemke and Young, 2021). Via fMRI, a highly specific activation in the right ventral tegmental area (VTA) and in the right caudate nucleus in response to pictures of dearly loved ones was identified in 17 human volunteers. Both are areas associated with the dopaminergic reward system in mammals, including humans, and are associated with both reward and motivation. The subcortical dopaminergic pathways are part of a 'universal arousal complex' that initiates romantic love, which is considered a motivational system that triggers not a specific but a variety of emotions, resulting in a prominent activation of the VTA and the caudate nucleus (Fisher et al., 2005). Sockman and Lyons (2017) focused on telencephalic regions of Lincoln's Sparrows (Melospiza lincolnii), i.e., the CMM and caudomedial nidopallium (NCM), which are known to mediate attention and (vocal) perception. In these brain regions, they examined neuromodulatory changes in monoaminergic activity in the context of female song preferences during mate choice. Reflecting the females' assessment of the song scenery as attractive or pleasant, the monoaminergic response of the CMM and NCM changed. For instance, moving between a very pleasant to a less pleasant song scenery, the pleasant scenery increased the threshold for an adaptive behavioral response (i.e., turning toward male song), thereby mirroring behavioral plasticity in response to changing signaling environments in the sexual context.

\section{SEX-SPECIFIC COGNITIVE PERFORMANCE AND PERSONALITY}

In view of as well as beyond sexual and/or social contexts, individuals may differ in numerous ways when dealing with cognitive tasks. For instance, they may differ in their speed and/or accuracy in solving the task ('performance level', Shettleworth, 2010). Moreover, they may differ in the way they evaluate and respond to a new, previously unknown task (personality and 'cognitive style', e.g., Sih and Del Giudice, 2012; Thornton and Lukas, 2012; Mazza et al., 2018). Hence, all (cognitive) processes related to mate choice are determined substantially by an individual's personality as well. To name only two outmost examples, an individual can proceed a given task quickly, boldly, and maybe impetuously. Alternatively, it can approach the same task very slowly and cautiously, but perhaps act more precisely. However, the mere existence of inter-individual differences does not imply the existence of personality, as personality presupposes stable inter-individual differences. Consequently, behavioral differences cannot equate with personality. Nevertheless, both dimensions mutually interact. Morphological, physiological, and plastic behavioral sex differences have been described consistently in many animal groups across taxa (e.g., Iwaniuk, 2017; Vallortigara and Versace, 2017; Cummings, 2018; Darda et al., 2018; Turano et al., 2018; Luders and Kurth, 2020; Kurth et al., 2020). These could derive from the different roles both sexes perform in their social environment (e.g., brood/nest care, social training by mothers, defense and food provisioning by fathers), which are frequently instrumental in shaping and being shaped by personality traits. The growing body of evidence suggests that an individual's personality shapes both its cognitive style and its cognitive performance. Both are determined by the particular cognitive domain the cognitive test is designed to examine. Therefore, a growing number of studies are now attempting to establish a link between the determinants of an individual's cognitive performance, its cognitive style, and the respective cognitive domain (Carere and Locurto, 2011; Sih and Del Giudice, 2012; Guillette et al., 2017; Dougherty and Guillette, 2018; Wallace et al., 2020). Dougherty and Guillette (2018) provided a comprehensive meta-analysis on 19 species ranging from mammals and birds to reptiles, fish, and even insects to explore the interactions between animal personality in terms of an individual's exploration, boldness, activity, aggression and sociability patterns and an individual's cognitive skills in terms of cognitive flexibility and error ratios in initial and reversal learning tasks. Sex was determined one of the major variables influencing the observed associations across all taxa (Dougherty and Guillette, 2018).

\section{Sex-Specific Cognitive Performance}

For instance, female guppies (Poecilia reticulata) showed greater behavioral flexibility than their male conspecifics in a visual discrimination task (Laland and Reader, 1999; Lucon-Xiccato and Bisazza, 2014, 2017a,b). In another study, two closely related molly species (Poecilia latipinna and Poecilia mexicana) and their more distant relative, the guppy ( $P$. reticulata) participated in an individual trial-and-error learning paradigm. Females of all three species were successful in all training phases of a visual dichotomous color discrimination task, followed by a series of reversal learnings. In contrast to the successful females, guppy males failed to learn even the general test paradigm. While no sex differences were observed in sailfin mollies ( $P$. latipinna), closely related Atlantic molly males ( $P$. mexicana) were clearly superior to females in all tasks they were assigned to, with some of them even reaching the one-trial learning level (Fuss and Witte, 2019). Moreover, Atlantic molly males performed significantly better in a socially learned visual dichotomous color discrimination task accompanied by serial reversals by inhibiting their prior response faster than their respective conspecific females (Fuss et al., 2021). Thus, what seemed to indicate an universal mechanism across different taxa with females responding clearly more flexible (e.g., observed in primates, rodents, domestic poultry, and teleosts) appears to be reversed in this fish species. Putatively, the observed sex differences in performance level, cognitive style and personality may account for the different sex roles in mating competition, mate choice, or complex sexual and social interactions in general, resulting from different selection pressures on both sexes during sexual selection. However, although cognitive sex differences appear to be present in many species across all taxonomic groups (e.g., fish: Lucon-Xiccato and Bisazza, 2017b; Cummings, 2018; birds: Kosarussavadi et al., 2017; mammals: Koss and Frick, 2016; 
Mazza et al., 2018, 2019), the range of excellent to rather poor cognitive abilities between and within taxa appear to fluctuate greatly (Shaw and Schmelz, 2017). The same applies to individuals of the same species and even domain-specifically to a single individual (Titulaer et al., 2012; Carazo et al., 2014; Mamuneas et al., 2015; Lucon-Xiccato and Bisazza, 2016, 2017b; Etheredge et al., 2018; Wallace et al., 2020). Beyond influencing determinants such as, for instance, ecology, life history, or social context, an alternative explanation for the enormous variability in cognitive capabilities observed across individuals, species, or taxa is merely methodological. Frequently, an array of different cognitive tests is used assessing both the same but also different cognitive traits. Indeed, this sometimes confounds the comparison of different results severely.

\section{Reflection in the Brain}

By now, many studies suggest a reflection of sex-specific along with associated personality-driven behaviors in the brain. Examples include different levels of and different responses to steroid hormones (e.g., Manson, 2008; Carroll et al., 2010; Lenz and McCarthy, 2010; McEwen and Milner, 2017), distinct expression profiles of neuronal genes [e.g., immediate early genes (IEGs); e.g., Banerjee et al., 2013; Chow et al., 2013; Yagi et al., 2016, 2017; Kosarussavadi et al., 2017; Gegenhuber and Tollkuhn, 2019, 2020] indicating increased or decreased activity in specific brain regions, or even different brain sizes (e.g., Kotrschal et al., 2013; Chen et al., 2015; Corral-López et al., 2017a,b). Thus, a change in cellular processes regularly induces a change in gene expression. Characteristic changes in gene expression reside in brain regions specific to sexual behavior such as mate competition, mate choice, or social behavior such as aggression between males or females of the same or a different species. Any form of learning, whether long-term learning driven by life-history experiences or short-term learning driven by learned mate choice behavior or innovativeness in an (acute) problem-solving task, is accompanied by a series of tightly coordinated changes in gene activity in the relevant brain microstructure. This also changes the coordinated processes of a single or multiple neuronal circuits, which in turn induce situational changes and adaptations in behavior (compare Baker et al., 2017 for review). Consequently, complex gene expression (e.g., IEGs, neurohistochemistry, emission of secondary, retro- or anterograde messengers in the brain, etc.) and neuronal stimulus processing, which constitute the basis of an adapted reaction, are interconnected closely. Thus, combining information from genetics such as candidate gene analysis, bioinformatics and behavioral biology, e.g., on (cognitive) behavioral flexibility will help to reveal genome mapping, neuronal and neurohistochemical mechanisms of complex behavior particularly in the context of mate choice and, more broadly, in adaptive evolutionary contexts (Baker et al., 2017). Delclos et al. (2020) observed general, although not brain regionspecific alterations in neuronal gene expression in response to different social and sexual contexts using transcriptomic profiles of both the sensory periphery and whole brains of female swordtail fish (Xiphophorus birchmanni). Along a shy-bold personality axis, conspecific encounters triggered an increased expression of immune-associated genes, olfactory and visual genes, and genes associated with fear, learning, and memory in visually and chemically exposed individuals. Also, visually and chemically heterospecific encounters led to an increased expression of genes associated with neurogenesis, synaptic plasticity, and social decision making, possibly indicating a stress coping strategy. For instance, neuroligins such as $n \lg n 2 b$ or npysar reflected a pivotal role in distinguishing between both transcriptomic profiles (i.e., conspecific or heterospecific profile), as did stress-coping genes and social decision-making network signaling pathway genes. The social decision-making network (SDMN) is "a highly conserved network of forebrain and midbrain regions that evaluates the salience and rewarding properties of a social stimulus by integrating sensory information about the (social) environment with an individual's own condition and prior experience, eventually resulting in a behavioral choice. Evolutionarily ancient signaling pathways - such as steroid hormones, neuropeptides and biogenic amines - regulate SDMN function in the context of social behavior" (DeAngelis and Hofmann, 2020). Similar results were obtained in zebrafish (Danio rerio) tested for proactive or reactive stress coping styles in contextual fear learning to chemical alarm substance from donor conspecifics. They showed neural plasticity in activity-dependent expression patterns of neurotransmissionrelated genes (npas4a and gabbr1a) in the medial and lateral zones of the dorsal telencephalon (Dm, Dl) and in the supracommissural nucleus of the ventral telencephalon (Vs) (Baker and Wong, 2019, 2021). Accordingly, many personality traits are supported by basic neuronal and neuroendocrine circuits that are plastically organized in the same or very similar ways in most vertebrates (e.g., Hofmann et al., 2014) and invertebrates (e.g., Hartenstein, 2006). These circuits can be drawn upon in comparable pathways across species to regulate the individual developmental stages in response to extrinsic and intrinsic events. In male green anoles, an altered gene expression of calcium channels, integrin alpha10 , and androgen and secretin receptors in the ventromedial hypothalamus was observed in close association with boldness during social agonistic and sexual interactions with conspecifics (Kabelik et al., 2021). Kelly and Goodson (2014) elucidated the sex-specific roles of oxytocin- and vasopressin-expressing neurons in the paraventricular hypothalamus of male and female zebra finches (Taeniopygia guttata castanotis) in social stress, aggression, sociability, individual preference for either larger or smaller groups, and pair bonding. While decreased vasopressin expression resulted in decreased sociability in all finches, it resulted in higher levels of aggression in males but lower levels in females. Conversely, decreased oxytocin availability in female zebra finches elicited lower sociability, weaker pair bonding, and weaker stress coping. Interestingly, sex-specific changes were observed in opposite-sex aggression levels but not in same-sex aggression levels (Kelly and Goodson, 2014). Comparable sexspecific interactions between social behavioral traits (aggression, dominance) and vasopressin were reported in male and female Syrian hamsters, prairie voles and other mammals as well (compare Dumais and Veenema, 2016; Terranova et al., 2017 for review). Depending on the social system and the prevailing 
sex roles, males and females may prefer to mate with a similarly behaving mate (assortative mating preference) or, conversely, a differently behaving one (disassortative mating preference).

\section{FEMALE MATE CHOICE AND NEURONAL RESPONSE}

The neuronal involvement and the interplay of the prefrontal cortex, septum, hippocampus, amygdala, and hypothalamus (or the corresponding brain areas in non-mammals, respectively) in social interactions were observed in different species across different taxa.

\section{Sexual Information Influence Neuronal Activity}

In mammals, these brain areas receive projections from the pontine tegmentum (Nucleus incertus, NI). The NI network is involved in social recognition and has been found to modulate the activity of sensory, emotional and executive brain regions. In studies of same-sex or opposite-sex mating preferences and the role of learning in their development, the medial preoptic area (mPOA) was determined to be a key region in particular for olfactory mediated sexual preferences, which goes beyond the mere control of copulatory behavior (rats and mice: Pfaus et al., 2012; Xiao et al., 2012; Graham and Pfaus, 2013; Zhong et al., 2014; ferrets: Paredes and Baum, 1995; hamsters: Martinez and Petrulis, 2013). It receives and responds to sensory information pertaining the physiological state of a potential partner (e.g., its health condition, fitness, or stage in the reproductive cycle), precisely integrates rewarding aspects of mating, exhibits context-dependent motor control and, hence, seems essential for mate assessment. While excitotoxic NI lesions impaired the recognition of conspecifics, a concurrent egr-1 activation in the amygdala, septum and hypothalamus and egr-1 inhibition in the hippocampus appeared to support the modulating properties of the NI network (García-Díaz et al., 2019).

Another example of how sexual information on a preferred male can influence the neuronal activity of choosing females used IEGs (egr-1, cellular homolog of fos) as neuronal markers for brain activity in gravid cichlid females (Astatotilapia burtoni). Initially, females were allowed to choose between two phenotypically equivalent males, who then had to fight with one another. Seeing her preferred male win caused a significant activation of the social behavioral network (SBN) nuclei known to be associated with reproduction. However, if the preferred male lost the fight, the activation of fearassociated nuclei in the lateral septum was induced. Hence, sexual information in the context of mate choice and its (anticipated) consequences powerfully activated specific parts of the female brain, independent of the actual social interaction (Desjardins et al., 2010). When exploring mate preference, aversion and sexual cognition in female northern swordtail brains (Xiphophorus nigrensis), nonapeptide gene expression (isotocin, vasotocin) was observed to differ depending on the sexual context associated with affiliation. Conversely, synaptic plasticity genes such as neuroserpin, neuroligin-3, tyrosine hydroxylase (TH1), and NMDAR responded merely to sexual contexts with distinct expression patterns. Females subjected to different mate choice contexts (large courting males, small coercive males or both) showed significantly higher neuroligin-3 expression levels in the medial and lateral telencephalon (Dm, Dl), the ventral zone of periventricular hypothalamus (HV), the POA and the ventral zone of the ventral telencephalon $(\mathrm{Vv})$, which are associated with sexual and social behavior. While no context- or behavior-related changes in TH1 mRNA expression patterns were observed in any brain region linked to female preference, neuroligin-3 levels were closely linked to mate choice contexts involving many courting male phenotypes. Thus, the aforementioned forebrain regions were predominantly involved in the processing of information on potential mates, being selectively supported by large parts of the brain with regard to the respective mate choice context (Wong et al., 2012; Wong and Cummings, 2014).

\section{Genes, Pathways, and Brain Regions Associated With Mate Choice and Learning}

Moreover, genes, pathways, and brain regions, which are considered to be closely associated with mate choice and learning appeared to be involved. Following preference tests of female mosquitofish (Gambusia affinis) choosing between female or coercive male conspecifics as well as between coercive or courting male heterospecifics ( $P$. latipinna), the expression levels of neuroserpin, egr-1, and early $B$ were examined by whole-brain gene expression analyses. Surprisingly, there was a positive association between the upregulation of the genes under investigation in view of courting heterospecies, which was absent in coercive heterospecies. The observed neuronal response was consistent with female mate preference, respectively. At the same time, older choice-experienced females chose courting males more quickly and ignored the coercive ones than younger females, suggesting previous learning experiences (Wang et al., 2014). Moreover, neuroserpin and neuroligin-3 were observed to be strongly expressed in female mosquitofish (G. affinis) in mate choice events, but the same candidate genes were downregulated in female swordtails (X. nigrensis) in a similar but social context. Conversely, neuroserpin and neuroligin-3 were expressed progressively in asocial and movement situations. This divergent gene response seems to perfectly mirror the different mate choice behavior of both species, with mosquitofish females choosing large, colorful males, while swordtail females try to avoid coercive males (Lynch et al., 2012). In the three poeciliid species under investigation, previously acquired mate choice experiences as well as memory retention of these experiences appear to play a determining role in future encounters and, therefore, appear to require some degree of cognitive ability.

Genes associated with prosociality were found to have higher predictive power for social contexts that differed by social vigilance. Similarly, genes associated with synaptic plasticity and learning were strongly tied to mate choice contexts. Blocking these important synaptic plasticity processes in the brain caused female preference to be suppressed. Gene expression and 
pharmacological manipulations in female northern swordtails suggest that selecting a mate involves sexual cognition and, hence, neuromolecular processes associated with learning at cellular (i.e., synaptic plasticity genes) and local (i.e., amygdala and hippocampus) levels (compare Cummings, 2015 for a review).

\section{Acoustic Communication as an Example of Neuromolecular Interaction}

In frogs (Spea bombifrons, P. pustulosus), the processing of acoustic signals in the midbrain plays an important role in mate choice (phonotaxis). For instance, acoustic communication signals from a wide range of animals occupy a large part of the biologically relevant frequency spectrum and require sophisticated midbrain integration and processing. They are frequently subject to (e.g., seasonal or diurnal) temporal variations, as some species of a wide array of taxa ranging from birds, insects, amphibians, mammals to fish, tend to be nocturnal, while others are diurnal, resulting in a constantly changing frequency and sequence composition of the soundscape (e.g., Ruppé et al., 2015; Ferreira et al., 2018; Gottesman et al., 2020). Female túngara frogs (P. pustulosus) expressed comparable preferences for courtship calls at low and medium noise densities, but no preference at high noise densities, which diminished their decision-making accuracy (Coss et al., 2021). However, mating preference can be predicted more accurately by the activity of the estradiol-gated, acoustically sensitive POA (as part of a sensory-endocrine circuit), which integrates forebrain inputs to the midbrain auditory response and, subsequently, influences motor responses directly via descending projections to the medulla and spinal cord. In addition, the basal forebrain including the POA, septum and Nucleus accumbens (Chakraborty and Burmeister, 2015) responds to mating calls, with the POA providing an increased production of Gonadotropin Releasing Hormone (GnRH; Burmeister and Wilczynski, 2005). Thus, many different regions of the SBN appear to be involved in evaluating mating calls, whereby the sensory system filters for relevant signals to which the POA attributes a contextdependent level of importance (Burmeister, 2017; Taylor et al., 2019). In summary, the involvement of the POA in mate choice and mate preference has been demonstrated across several taxa, including primate and non-primate mammals, amphibians and fish and, thus, appears to be a highly preserved mechanism.

\section{BRAIN SIZE, COGNITIVE ABILITY AND MATE CHOICE}

Present literature appears to support the 'social intelligence hypothesis', according to which relatively big brains and higher cognitive abilities have developed to cope with the variable, sometimes apparently erratic behavior of potential mates or other group members in general. Larger brain size appears to be evident primarily in species that (a) live in larger social groups, (b) experience a greater reliance on social learning in response to a variable environment, and (c) exhibit a prolonged reproductive period (Holekamp and Benson-Amram, 2017).

\section{Brain Size Predicts Mate Assessment and Behavioral Plasticity in Guppies}

Kotrschal et al. (2014) linked brain size as a proxy for cognitive ability to personality and behavioral plasticity of guppies $(P$. reticulata) by artificially selecting for large and small brain size in the laboratory. The guppy females' brain size apparently greatly impacts the assessment of male attractiveness during mate choice. In turn, guppy male brain size appears to strongly interfere with the judgment of female quality during male mate choice as well. Likewise, brain size along with environmental complexity seem to play a pivotal role in the mating behavior of both male and female guppies (Corral-López, 2017; CorralLópez et al., 2017a,b). In another study (Herczeg et al., 2019), guppies were initially kept in social groups in enriched aquaria. Subsequently, they were separated in empty aquaria where they were exposed to visual predator stimuli. Prior to experiments, the researchers expected a stronger response to stress (indicated by lowered behavioral activity), to be followed by faster habituation (indicated by rapid increases in behavioral activity) of the largebrained individuals over time relative to the small-brained ones. Both selection lines (i.e., large-brained and small-brained fish) showed progressive sensitization (i.e., increasing risk aversion) to predator stimuli, thus, providing support for the hypothesis on the relationship between brain size and behavioral plasticity. The extent of individual or sex-specific personality differences remained unaffected by the selected brain size (Herczeg et al., 2019). Likewise, using two lineages selected for their relative brain sizes and different cognitive abilities, Corral-López et al. (2020) examined the mate choice behavior of guppies in the context of predation threat and different sex ratios. While female guppies with relatively larger brains became increasingly willing to copulate as predation threat decreased (female biased sex ratio), so did individuals with smaller brains in male guppies, which also appeared more aggressive at the same time. However, females did not show a preference for large-brained males, which may indicate an influence of brain size on the mating propensity of male guppies.

\section{Linking Brain Size and Cognitive Ability to Social-Sex Selection Pressures}

It has been widely assumed that relatively larger brains comprise a higher number of neurons and connections between them, hence, leading to better cognitive abilities. However, critical of the link between relative brain size and cognitive ability is that there are virtually no studies actually examining this phenomenon. In order to assess cognitive ability in association with the relevant neuronal substrates properly, important parameters such as interconnectivity and the number of neurons involved [as a measure of (higher) neuron density] need to be determined along with the (relative) brain size. Analyses of the two large- and small-brained guppy strains, respectively, showed that breeding favoring one brain size or the other did indeed result in shifts in the number of neurons both throughout the brain and, particularly, in the telencephalon. At the same time, neuronal density correlated negatively with individual brain size (Marhounová et al., 2019). Hence, this study appears 
to confirm a close association of individual brain size with neuron number, and thus putatively, with cognition - at least within the fish species under investigation. An effect of brain size on female learning performance has been reported in swordtails (Xiphophorus multilineatus) subjected to a classical conditioning paradigm as well (Griebling et al., 2020). In the context of mating and pair bonding, the brains of seven closely related cichlid species with different sexual behaviors from Lake Tanganyika located between Tanzania, Zambia, Burundi, and Congo were studied volumetrically. Significantly greater telencephalon volumes were found in species with predominantly monogamous mating systems compared to polygamous cichlid species (Pollen et al., 2007). These results were probably attributable less to mating behavior than to shared parental brood care and living in complex habitats, the latter requiring concurrently considerably higher cognitive abilities, for instance, in spatial orientation. Similar results have also been reported in different stickleback species, where the cognitive challenges of parenting resulted in significant sexual dimorphism in brain size, particularly in the brain of the respective brood-caring parent (Gonzalez-Voyer et al., 2009; Kotrschal et al., 2012; Samuk et al., 2014; Toli et al., 2017). In more than thirty cichlid species, the mating system (polygamous and monogamous) was observed to significantly influence sex differences in telencephalon size, with sexual dimorphisms being present only in polygamous species (male telencephalon $>$ female telencephalon) (GonzalezVoyer and Kolm, 2010). Likewise, Holekamp and BensonAmram (2017) sought to link brain size in spotted hyaenas to their enhanced cognitive abilities and strikingly pronounced social skills. As predicted by the social intelligence hypothesis, spotted hyaenas have considerably larger brains and enlarged frontal cortices compared to less social hyaena species. Frontal cortex volume was significantly greater in male sexually mature spotted hyenas than in females despite equal endocranial volume, although males and females of this species face similar requirements regarding success level and size of hunting territory when pursuing vertebrate prey (e.g., Boydston et al., 2005; Holekamp and Benson-Amram, 2017). Even in humans, the capacity for behavioral flexibility in response to environmental changes is considered an important determinant in the evolution of the human brain (Holekamp and Benson-Amram, 2017).

\section{The Cognitive Buffer Hypothesis}

These findings seem to support the social intelligence hypothesis at first glance. However, other studies revealed that domaingeneral cognitive abilities did not develop in response to social-sex selection pressures, but predominantly in response to permanently changing and, therefore, novel environmental conditions in general, which are followed by alterations in the associated social context ('cognitive buffer hypothesis'; Holekamp and Benson-Amram, 2017). The cognitive buffer hypothesis derives from observations particularly in primates by means of positive correlations between brain size and longevity, taking into account other factors such as sex, social structure, and life history (Allman et al., 1993; Hofman, 1993; Reader and Laland, 2002). In this context, a larger brain seems to be associated with both longer life and a slower pace of life, thus also influencing important life history traits such as development or sexual or reproductive traits.

Therefore, in summary, the cognitive buffer hypothesis may provide a framework for explaining the evolution of vertebrate brain size (Jiménez-Ortega et al., 2020). A longer lifespan would allow individuals to exploit their costly investment in brain size to the maximum by, for instance, devoting more time to finding innovative solutions to problems that would otherwise jeopardize their survival and reproductive success (Sol and Lefebvre, 2000; Shultz et al., 2005; Sol et al., 2005, 2008). Moreover, learning allows for a certain degree of behavioral flexibility to deal with challenges in the animate and inanimate environment, for instance in the context of reduced food availability, increased predation risk, or a mating system with frequent coercive copulations (Richerson and Boyd, 2000; Reader and MacDonald, 2003; Sol, 2009a,b; Sol et al., 2016). However, individual, speciesor sex-specific brain size, its consequences for cognitive ability and mate choice are under intense discussion and far from being clear-cut. Nevertheless, the examples presented here show that there appears to be a coherency, at least in fish and mammals, which is worth continuing to illuminate. Hence, future studies should try to elucidate further the evolution of vertebrate brain size along with its consequences for cognitive mate choice.

\section{CONCLUDING REMARKS AND FUTURE PERSPECTIVES}

This review aimed to throw a spotlight on the neuronal prerequisites, networks and processes supporting the interaction between mate choice, sex roles and social cognition, hence, supporting cognitive mate choice. Considering the numerous exciting studies, mainly covering the three largest vertebrate groups of mammals, birds and fish, there is support that the neuronal activity of males and females indeed differs with respect to social cognition. In terms of results derived from gene-based neuronal activity markers (IEGs and SPGs), modulatory effects of neurotransmitters and hormones or even fMRI studies, there are ample indications supporting the idea that the sex as well as the respective sex role within the prevalent mating system is mirrored at a neuronal level, at least in individual brain regions. The same can be assumed for the cognitive capabilities affecting mate choice, just as mate choice affects cognitive abilities in both sexes. An appropriate behavioral response is supported and triggered by the associated neuronal and molecular prerequisites. Hence, carefully designed behavioral studies together with stateof-the-art neuroanatomical techniques will allow for testing cause, effect, and (modulatory) interactions of an observed behavioral pattern and the substrates decisively coordinating an appropriate response.

So far, however, our knowledge largely relies on the observation of a confined set of networks (e.g., SBN and SDNM) or distinct recruited brain regions (in particular the associative areas of the telencephalon, the sensory areas of the telencephalon and the midbrain as well as their respective correlates across taxa). Many crucial intermediary steps, associations, and, accordingly, many cause-and-effect relationships along with the 
truly relevant level of brain organization remain obscure to us so far. For instance, we do not know how precisely females assess the cognitive performance of males, if it is perhaps reflected in any physical attributes, or how the brain responds to merely observed mate choice situations. When observing sexual social interactions, the brain and/or the neuronal substrates involved could hypothetically respond in the same way as when drawing own decisions. In analogy to the mirror neurons known, for instance, from mammals, the neuronal substrates of an individual could adaptively modulate their activity and revert to the observed, and, hence, learned and memorized information, when an individual actually decides and effects its own decision. By comparing many observed mate choice situations, a kind of 'blueprint' may develop, possibly allowing an individual's mate choice decisions to progress significantly faster, more efficiently, and more accurately. In order to bridge this gap in knowledge, future studies should strive to integrate the behavioral and neurobiological dimensions in the context of cognitive mate choice. In view of the technical progress and novel methods in behavioral studies and neurobiology, we

\section{REFERENCES}

Adolphs, R. (1999). Social cognition and the human brain. Trends Cogn. Sci. 3, 469-479.

Ah-King, M., and Ahnesjö, I. (2013). The "sex role" concept: an overview and evaluation. Evol. Biol. 40, 461-470. doi: 10.1007/s11692-0139226-7

Alcock, J. (2001). Animal Behavior: An Evolutionary Approach (No. QL751. A42 1984.). Sunderland: Sinauer Associates.

Allman, J., McLaughlin, T., and Hakeem, A. (1993). Brain weight and life-span in primate species. Proc. Natl. Acad. Sci. U.S.A. 90, 118-122. doi: 10.1073/pnas.90. 1.118

Amundsen, T. (2018). Sex roles and sexual selection: lessons from a dynamic model system. Curr. Zool. 64, 363-392. doi: 10.1093/cz/zoy036

Arnold, A. P. (2004). Sex chromosomes and brain gender. Nat. Rev. Neurosci. 5, 701-708. doi: 10.1038/nrn1494

Ashley, N. T., and Demas, G. E. (2017). Neuroendocrine-immune circuits, phenotypes, and interactions. Horm. Behav. 87, 25-34. doi: 10.1016/j.yhbeh. 2016.10.004

Avey, M. T., Phillmore, L. S., and MacDougall-Shackleton, S. A. (2005). Immediate early gene expression following exposure to acoustic and visual components of courtship in zebra finches. Behav. Brain Res. 165, 247-253. doi: 10.1016/j.bbr. 2005.07.002

Baker, M. R., and Wong, R. Y. (2019). Contextual fear learning and memory differ between stress coping styles in zebrafish. Sci. Rep. 9:9935. doi: 10.1038/s41598019-46319-0

Baker, M. R., and Wong, R. Y. (2021). Npas4a expression in the teleost forebrain is associated with stress coping style differences in fear learning. Sci. Rep. 11:12074. doi: 10.1038/s41598-021-91495-7

Baker, M. R., Hofmann, H. A., and Wong, R. Y. (ed.) (2017). "Neurogenomics of behavioural plasticity in socioecological contexts," in eLS. (Hoboken, NJ: John Wiley \& Sons, Ltd). doi: 10.1002/9780470015902.a0026839

Banerjee, S. B., Dias, B. G., Crews, D., and Adkins-Regan, E. (2013). Newly paired zebra finches have higher dopamine levels and immediate early gene Fos expression in dopaminergic neurons. Eur. J. Neurosci 38, 3731-3739. doi: 10.1111/ejn.12378

Bayne, T., Brainard, D., Byrne, R. W., Chittka, L., Clayton, N., Heyes, C., et al. (2019). What is cognition? Curr. Biol. 29, R608-R615.

Bloch, N. I., Corral-López, A., Buechel, S. D., Kotrschal, A., Kolm, N., and Mank, J. E. (2018). Early neurogenomic response associated with variation in guppy female mate preference. Nat. Ecol. Evol. 2, 1772-1781. doi: 10.1038/s41559018-0682-4 may anticipate an array of fascinating lessons, discoveries, and insights to shed light on the complex relationship of mate choice and cognition.

\section{AUTHOR CONTRIBUTIONS}

The author confirms being the sole contributor of this work and has approved it for publication.

\section{ACKNOWLEDGMENTS}

I thank Klaudia Witte for the opportunity to write the manuscript and her helpful comments to improve it. I thank Nils Krützfeldt for proofreading the manuscript. I also thank the University of Siegen for the financial support provided through its Open Access Publication Fund. Last but not least, I thank the guest editor for inviting me to write about this research topic, as well as both reviewers for their time and support.

Bloch, N. I., Corral-López, A., Buechel, S. D., Kotrschal, A., Kolm, N., and Mank, J. E. (2021). Different mating contexts lead to extensive rewiring of female brain coexpression networks in the guppy. Genes Brain Behav. 20:e12697. doi: $10.1111 / \mathrm{gbb} .12697$

Blumenfeld-Katzir, T., Pasternak, O., Dagan, M., and Assaf, Y. (2011). Diffusion MRI of structural brain plasticity induced by a learning and memory task. PLoS One 6:e20678. doi: 10.1371/journal.pone.0020678

Bolhuis, J. J., and Honey, R. C. (1998). Imprinting, learning and development: from behaviour to brain and back. Trends Neurosci. 21, 306-311. doi: 10.1016/s01662236(98)01258-2

Boydston, E. E., Kapheim, K. M., Van Horn, R. C., Smale, L., and Holekamp, K. E. (2005). Sexually dimorphic patterns of space use throughout ontogeny in the spotted hyena (Crocuta crocuta). J. Zool. 267, 271-281. doi: 10.1017/ s0952836905007478

Bozon, B., Davis, S., and Laroche, S. (2002). Regulated transcription of the immediate-early gene Zif268: mechanisms and gene dosage-dependent function in synaptic plasticity and memory formation. Hippocampus 12, 570577. doi: 10.1002/hipo.10100

Bressler, S. C., and Baum, M. J. (1996). Sex comparison of neuronal Fos immunoreactivity in the rat vomeronasal projection circuit after chemosensory stimulation. Neuroscience 71, 1063-1072. doi: 10.1016/0306-4522(95)00493-9

Burmeister, S. S. (2017). Neurobiology of female mate choice in frogs: auditory filtering and valuation. Integr. Comp. Biol. 57, 857-864. doi: 10.1093/icb/icx098

Burmeister, S. S., and Wilczynski, W. (2005). Social signals regulate gonadotropinreleasing hormone neurons in the green treefrog. Brain Behav. Evol. 65, 26-32. doi: $10.1159 / 000081108$

Burmeister, S. S., Jarvis, E. D., and Fernald, R. D. (2005). Rapid behavioral and genomic responses to social opportunity. PLoS Biol. 3:e363. doi: 10.1371/ journal.pbio.0030363

Carazo, P., Noble, D. W., Chandrasoma, D., and Whiting, M. J. (2014). Sex and boldness explain individual differences in spatial learning in a lizard. Proc. $R$. Soc. B Biol. Sci. 281:20133275. doi: 10.1098/rspb.2013.3275

Carere, C., and Locurto, C. (2011). Interaction between animal personality and animal cognition. Curr. Zool. 57, 491-498. doi: 10.1093/czoolo/57.4.491

Carroll, J. C., Rosario, E. R., Kreimer, S., Villamagna, A., Gentzschein, E., Stanczyk, F. Z., et al. (2010). Sex differences in $\beta$-amyloid accumulation in 3xTg-AD mice: role of neonatal sex steroid hormone exposure. Brain Res. 1366, 233-245. doi: 10.1016/j.brainres.2010.10.009

Caspers, B. A., Gagliardo, A., and Krause, E. T. (2015). Impact of kin odour on reproduction in zebra finches. Behav. Ecol. Sociobiol. 69, 1827-1833. doi: 10.1007/s00265-015-1995-9 
Caspers, B. A., Hagelin, J. C., Paul, M., Bock, S., Willeke, S., and Krause, E. T. (2017). Zebra Finch chicks recognise parental scent, and retain chemosensory knowledge of their genetic mother, even after egg cross-fostering. Sci. Rep. 7:12859. doi: 10.1038/s41598-017-13110-y

Chakraborty, M., and Burmeister, S. S. (2015). Effects of estradiol on neural responses to social signals in female túngara frogs. J. Exp. Biol. 218, 3671-3677. doi: $10.1242 /$ jeb. 127738

Chen, Y. C., Harrison, P. W., Kotrschal, A., Kolm, N., Mank, J. E., and Panula, P. (2015). Expression change in Angiopoietin-1 underlies change in relative brain size in fish. Proc. R. Soc. B Biol. Sci. 282:20150872. doi: 10.1098/rspb.2015.0872

Choleris, E., Clipperton-Allen, A. E., Phan, A., and Kavaliers, M. (2009). Neuroendocrinology of social information processing in rats and mice. Front. Neuroendocrinol. 30:442-459. doi: 10.1016/j.yfrne.2009.05.003

Choleris, E., Clipperton-Allen, A. E., Phan, A., Valsecchi, P., and Kavaliers, M. (2012). Estrogenic involvement in social learning, social recognition and pathogen avoidance. Front. Neuroendocrinol. 33:140-159. doi: 10.1016/j.yfrne. 2012.02.001

Choleris, E., Galea, L. A., Sohrabji, F., and Frick, K. M. (2018). Sex differences in the brain: implications for behavioral and biomedical research. Neurosci. Biobehav. Rev. 85, 126-145. doi: 10.1016/j.neubiorev.2017.07.005

Chow, C., Epp, J. R., Lieblich, S. E., Barha, C. K., and Galea, L. A. (2013). Sex Differences In Neurogenesis And Activation Of New Neurons In Response To Spatial Learning,Doctoral dissertation, University of British Columbia.

Corral-López, A. (2017). The Link Between Brain Size, Cognitive Ability, Mate Choice and Sexual Behaviour in the Guppy (Poecilia reticulata). Doctoral dissertation. Stockholm: Department of Zoology, Stockholm University.

Corral-López, A., Bloch, N. I., Kotrschal, A., van der Bijl, W., Buechel, S. D., Mank, J. E., et al. (2017a). Female brain size affects the assessment of male attractiveness during mate choice. Sci. Adv. 3:e1601990. doi: 10.1126/sciadv. 1601990

Corral-López, A., Garate-Olaizola, M., Buechel, S. D., Kolm, N., and Kotrschal, A. (2017b). On the role of body size, brain size, and eye size in visual acuity. Behav. Ecol. Sociobiol. 71:179. doi: 10.1007/s00265-017-2408-z

Corral-López, A., Romensky, M., Kotrschal, A., Buechel, S. D., and Kolm, N. (2020). Brain size affects responsiveness in mating behaviour to variation in predation pressure and sex ratio. J. Evol. Biol 33, 165-177. doi: 10.1111/jeb. 13556

Coss, D. A., Hunter, K. L., and Taylor, R. C. (2021). Silence is sexy: soundscape complexity alters mate choice in túngara frogs. Behav. Ecol. 32, 49-59. doi: 10.1093/beheco/araa091

Cummings, M. E. (2015). The mate choice mind: studying mate preference, aversion and social cognition in the female poeciliid brain. Anim. Behav. 103, 249-258. doi: 10.1016/j.anbehav.2015.02.021

Cummings, M. E. (2018). Sexual conflict and sexually dimorphic cognitionreviewing their relationship in poeciliid fishes. Behav. Ecol. Sociobiol. 72:73.

Cummings, M. E., and Ramsey, M. E. (2015). Mate choice as social cognition: predicting female behavioral and neural plasticity as a function of alternative male reproductive tactics. Curr. Opin. Behav. Sci. 6, 125-131. doi: 10.1016/j. cobeha.2015.10.001

Darda, K. M., Butler, E. E., and Ramsey, R. (2018). Functional specificity and sex differences in the neural circuits supporting the inhibition of automatic imitation. J. Cogn. Neurosci. 30, 914-933. doi: 10.1162/jocn_a_01261

Davis, S., Bozon, B., and Laroche, S. (2003). How necessary is the activation of the immediate early gene zif268 in synaptic plasticity and learning? Behav. Brain Res. 142, 17-30. doi: 10.1016/s0166-4328(02)00421-7

DeAngelis, R. S., and Hofmann, H. A. (2020). Neural and molecular mechanisms underlying female mate choice decisions in vertebrates. J. Exp. Biol. 223:jeb207324. doi: 10.1242/jeb.207324

Delclos, P. J., Forero, S. A., and Rosenthal, G. G. (2020). Divergent neurogenomic responses shape social learning of both personality and mate preference. J. Exp. Biol. 223:jeb220707. doi: 10.1242/jeb.220707

Desjardins, J. K., Klausner, J. Q., and Fernald, R. D. (2010). Female genomic response to mate information. Proc. Natl. Acad. Sci. U.S.A. 107, 21176-21180. doi: 10.1073/pnas.1010442107

Di Giorgio, E., Loveland, J. L., Mayer, U., Rosa-Salva, O., Versace, E., and Vallortigara, G. (2017). Filial responses as predisposed and learned preferences: early attachment in chicks and babies. Behav. Brain Res. 325, 90-104. doi: 10.1016/j.bbr.2016.09.018
DiBenedictis, B. T., Ingraham, K. L., Baum, M. J., and Cherry, J. A. (2012). Disruption of urinary odor preference and lordosis behavior in female mice given lesions of the medial amygdala. Physiol. Behav. 105, 554-559. doi: 10. 1016/j.physbeh.2011.09.014

Dougherty, L. R., and Guillette, L. M. (2018). Linking personality and cognition: a meta-analysis. Philos. Trans. R. Soc. Lond. B Biol. Sci. 373:20170282. doi: $10.1098 /$ rstb. 2017.0282

Døving, K. B., and Trotier, D. (1998). Structure and function of the vomeronasal organ. J. Exp. Biol. 201, 2913-2925. doi: 10.1242/jeb.201.21.2913

Dragunow, M. (1996). A role for immediate-early transcription factors in learning and memory. Behav. Gen. 26, 293-299. doi: 10.1007/bf02359385

Driemeyer, J., Boyke, J., Gaser, C., Büchel, C., and May, A. (2008). Changes in gray matter induced by learning-revisited. PLoS One 3:e2669. doi: 10.1371/journal. pone.0002669

Dukas, R. (2004). Evolutionary biology of animal cognition. Annu. Rev. Ecol. Evol. Syst. 35, 347-374. doi: 10.1146/annurev.ecolsys.35.112202.130152

Dumais, K. M., and Veenema, A. H. (2016). Vasopressin and oxytocin receptor systems in the brain: sex differences and sex-specific regulation of social behavior. Front. Neuroendocrinol. 40:1-23. doi: 10.1016/j.yfrne.2015.04.003

Ervin, K. S., Lymer, J. M., Matta, R., Clipperton-Allen, A. E., Kavaliers, M., and Choleris, E. (2015). Estrogen involvement in social behavior in rodents: rapid and long-term actions. Horm. Behav. 74, 53-76. doi: 10.1016/j.yhbeh.2015.05. 023

Etheredge, R. I., Avenas, C., Armstrong, M. J., and Cummings, M. E. (2018). Sexspecific cognitive-behavioural profiles emerging from individual variation in numerosity discrimination in Gambusia affinis. Anim. Cogn. 21, 37-53. doi: 10.1007/s10071-017-1134-2

Ewer, R. F. (1956). Imprinting in animal behavior. Nature 177, 227-228.

Ferreira, L. M., Oliveira, E. G., Lopes, L. C., Brito, M. R., Baumgarten, J., Rodrigues, F. H., et al. (2018). What do insects, anurans, birds, and mammals have to say about soundscape indices in a tropical savanna. J. Ecoacoust. 2, 1-17. doi: $10.22261 /$ jea.pvh6yz

Fisher, H., Aron, A., and Brown, L. L. (2005). Romantic love: an fMRI study of a neural mechanism for mate choice. J. Comp. Neurol. 493, 58-62. doi: 10.1002/cne. 20772

Fong, S., Buechel, S. D., Boussard, A., Kotrschal, A., and Kolm, N. (2019) Plastic changes in brain morphology in relation to learning and environmental enrichment in the guppy (Poecilia reticulata). J. Exp. Biol. 222:jeb200402. doi: 10.1242/jeb.200402

Froemke, R. C., and Young, L. J. (2021). Oxytocin, neural plasticity, and social behavior. Ann. Rev. Neurosci. 44, 359-381. doi: 10.1146/annurev-neuro102320-102847

Fuss, T., and Schluessel, V. (2018). Immediate early gene expression related to learning and retention of a visual discrimination task in bamboo sharks (Chiloscyllium griseum). Brain Struct. Funct. 223, 3975-4003. doi: 10.1007/ s00429-018-1728-8

Fuss, T., and Witte, K. (2019). Sex differences in color discrimination and serial reversal learning in mollies and guppies. Curr. Zool. 65, 323-332. doi: 10.1093/ cz/zoz029

Fuss, T., Flöck, S., and Witte, K. (2021). Sex-specific cognitive flexibility in Atlantic mollies when learning from male demonstrators exploring a new food source. Anim. Behav. 173, 9-19. doi: 10.1016/j.anbehav.2020.12.012

Gabor, C. S., Phan, A., Clipperton-Allen, A. E., Kavaliers, M., and Choleris, E. (2012). Interplay of oxytocin, vasopressin, and sex hormones in the regulation of social recognition. Behav. Neurosci. 126:97. doi: 10.1037/a002 6464

García-Díaz, C., Sánchez-Catalán, M. J., Castro-Salazar, E., García-Avilés, A., Albert-Gascó, H., de la Bárcena, S. S. S., et al. (2019). Nucleus incertus ablation disrupted conspecific recognition and modified immediate early gene expression patterns in 'social brain'circuits of rats. Behav. Brain Res. 356, 332-347. doi: 10.1016/j.bbr.2018.08.035

Geary, D. C. (2002). "Sexual selection and sex differences in social cognition," in Biology, Society, And Behavior: The Development Of Sex Differences In Cognition, eds A. V. McGillicuddy-De Lisi and R. De Lisi (Greenwich, CT: Ablex/Greenwood), 23-53.

Gegenhuber, B., and Tollkuhn, J. (2019). Sex differences in the epigenome: a cause or consequence of sexual differentiation of the brain? Genes 10:432. doi: 10 . 3390/genes 10060432 
Gegenhuber, B., and Tollkuhn, J. (2020). Signatures of sex: sex differences in gene expression in the vertebrate brain. Wiley Interdiscip. Rev. Dev. Biol. 9:e348.

George, I., Hara, E., and Hessler, N. A. (2006). Behavioral and neural lateralization of vision in courtship singing of the zebra finch. J. Neurobiol. 66, 1164-1173. doi: $10.1002 /$ neu. 20273

Giurfa, M., Zhang, S., Jenett, A., Menzel, R., and Srinivasan, M. V. (2001). The concepts of 891 'sameness' and 'difference' in an insect. Nature 410, 930-933. doi: $10.1038 / 35073582$

Golüke, S., Bischof, H. J., Engelmann, J., Caspers, B. A., and Mayer, U. (2019). Social odour activates the hippocampal formation in zebra finches (Taeniopygia guttata). Behav. Brain Res. 364, 41-49. doi: 10.1016/j.bbr.2019.02.013

Golüke, S., Dörrenberg, S., Krause, E. T., and Caspers, B. A. (2016). Female zebra finches smell their eggs. PLoS One 11:e0155513. doi: 10.1371/journal.pone. 0155513

Gonzalez-Voyer, A., and Kolm, N. (2010). Sex, ecology and the brain: evolutionary correlates of brain structure volumes in Tanganyikan cichlids. PLoS One 5:e14355. doi: 10.1371/journal.pone.0014355

Gonzalez-Voyer, A., Winberg, S., and Kolm, N. (2009). Social fishes and single mothers: brain evolution in African cichlids. Proc. R. Soc. B Biol. Sci. 276, 161-167. doi: 10.1098/rspb.2008.0979

Goodson, J. L. (2013). Deconstructing sociality, social evolution and relevant nonapeptide functions. Psychoneuroendocrinology 38, 465-478. doi: 10.1016/ j.psyneuen.2012.12.005

Gottesman, B. L., Francomano, D., Zhao, Z., Bellisario, K., Ghadiri, M., Broadhead, T., et al. (2020). Acoustic monitoring reveals diversity and surprising dynamics in tropical freshwater soundscapes. Freshw. Biol. 65, 117-132. doi: 10.1111/fwb. 13096

Gouda-Vossos, A., Nakagawa, S., Dixson, B. J., and Brooks, R. C. (2018). Mate choice copying in humans: a systematic review and meta-analysis. Adapt. Hum. Behav. Physiol. 4, 364-386. doi: 10.1007/s40750-018-0099-y

Graham, M. D., and Pfaus, J. G. (2013). Infusions of ascorbic acid into the medial preoptic area facilitate appetitive sexual behavior in the female rat. Physiol. Behav. 122, 140-146. doi: 10.1016/j.physbeh.2013.09.008

Griebling, H. J., Rios-Cardenas, O., Abbott, J., and Morris, M. R. (2020). A study of tactical and sexual dimorphism in cognition with insights for sexual conflict. Anim. Behav. 170, 43-50. doi: 10.1016/j.anbehav.2020.10.006

Guillette, L. M., Naguib, M., and Griffin, A. S. (2017). Individual differences in cognition and personality [Editorial]. Behav. Processes 134, 1-3. doi: 10.1016/j. beproc.2016.12.001

Hare, R. M., and Simmons, L. W. (2020). Ecological determinants of sex roles and female sexual selection. Adv. Stud. Behav. 52, 1-28. doi: 10.1016/bs.asb.2019. 11.001

Hare, R. M., and Simmons, L. W. (2021). Sexual selection maintains a femalespecific character in a species with dynamic sex roles. Behav. Ecol. 32, 609-616. doi: 10.1093/beheco/arab005

Hartenstein, V. (2006). The neuroendocrine system of invertebrates: a developmental and evolutionary perspective. J. Endocrinol. 190, 555-570. doi: $10.1677 /$ joe.1.06964

Harvey-Girard, E., Tweedle, J., Ironstone, J., Cuddy, M., Ellis, W., and Maler, L. (2010). Long-term recognition memory of individual conspecifics is associated with telencephalic expression of Egr-1 in the electric fish Apteronotus leptorhynchus. J. Comp. Neurol 518, 2666-2692. doi: $10.1002 / \mathrm{cne} .22358$

Hauber, M. E., Louder, M. I., and Griffith, S. C. (2021). The Natural History of Model Organisms: neurogenomic insights into the behavioral and vocal development of the zebra finch. Elife 10:e61849. doi: 10.7554/eLife.61849

Herczeg, G., Urszán, T. J., Orf, S., Nagy, G., Kotrschal, A., and Kolm, N. (2019). Brain size predicts behavioural plasticity in guppies (Poecilia reticulata): an experiment. J. Evol. Biol. 32, 218-226. doi: 10.1111/jeb.13405

Hess, E. H. (1959). Imprinting. Science 130, 133-141.

Hess, E. H. (1964). Imprinting in birds. Science 146, 1128-1139. doi: 10.1126/ science.146.3648.1128

Hofman, M. A. (1993). Encephalization and the evolution of longevity in mammals. J. Evol. Biol. 6, 209-227. doi: 10.1046/j.1420-9101.1993.6020209.x

Hofmann, H. A., Beery, A. K., Blumstein, D. T., Couzin, I. D., Earley, R. L., Hayes, L. D., et al. (2014). An evolutionary framework for studying mechanisms of social behavior. Trends Ecol. Evol. 29, 581-589. doi: 10.1016/j.tree.2014.07.008
Hoke, K. L., Ryan, M. J., and Wilczynski, W. (2008). Candidate neural locus for sex differences in reproductive decisions. Biol. Lett. 4, 518-521. doi: 10.1098/rsbl. 2008.0192

Holekamp, K. E., and Benson-Amram, S. (2017). The evolution of intelligence in mammalian carnivores. Interface Focus 7:20160108. doi: 10.1098/rsfs.2016. 0108

Immelmann, K. (1975). Ecological significance of imprinting and early learning. Annu. Rev. Ecol. Syst. 6, 15-37. doi: 10.1007/s10071-012-0514-x

Iwaniuk, A. N. (2017). "The evolution of cognitive brains in non-mammals," in Evolution Of The Brain, Cognition, And Emotion In Vertebrates, eds S. Watanabe, M. Hofman, and T. Shimizu (Tokyo: Springer), 101-124. doi: 10. 1007/978-4-431-56559-8_5

Jazin, E., and Cahill, L. (2010). Sex differences in molecular neuroscience: from fruit flies to humans. Nat. Rev. Neurosci. 11, 9-17. doi: 10.1038/nrn2754

Jiménez-Ortega, D., Kolm, N., Immler, S., Maklakov, A. A., and Gonzalez-Voyer, A. (2020). Long life evolves in large-brained bird lineages. Evolution 74, $2617-$ 2628. doi: $10.1111 /$ evo. 14087

Joiner, J., Piva, M., Turrin, C., and Chang, S. W. (2017). Social learning through prediction error in the brain. NPJ Sci. Learn. 2, 1-9.

Kabelik, D., Julien, A. R., Ramirez, D., and O'Connell, L. A. (2021). Social boldness correlates with brain gene expression in male green anoles. Horm. Behav. 133:105007. doi: 10.1016/j.yhbeh.2021.105007

Kanwisher, N., and Yovel, G. (2006). The fusiform face area: a cortical region specialized for the perception of faces. Philos. Trans. R. Soc. Lond. B Biol. Sci. 361, 2109-2128. doi: 10.1098/rstb.2006.1934

Kavaliers, M., and Choleris, E. (2017). Social cognition and the neurobiology of rodent mate choice. Integr. Comp. Biol. 57, 846-856. doi: 10.1093/icb/icx042

Kavaliers, M., Ossenkopp, K. P., and Choleris, E. (2019). Social neuroscience of disgust. Genes Brain Behav. 18:e12508. doi: 10.1111/gbb. 12508

Kelly, A. M., and Goodson, J. L. (2014). Hypothalamic oxytocin and vasopressin neurons exert sex-specific effects on pair bonding, gregariousness, and aggression in finches. Proc. Natl. Acad. Sci.U.S.A. 111, 6069-6074. doi: 10.1073/ pnas.1322554111

Kendrick, K. M., and Baldwin, B. A. (1987). Cells in temporal cortex of conscious sheep can respond preferentially to the sight of faces. Science 236, 448-450. doi: $10.1126 /$ science. 3563521

Kondo, Y., Sudo, T., Tomihara, K., and Sakuma, Y. (2003). Activation of accessory olfactory bulb neurons during copulatory behavior after deprivation of vomeronasal inputs in male rats. Brain Res. 962, 232-236. doi: 10.1016/ s0006-8993(02)03970-7

Kosarussavadi, S., Pennington, Z. T., Covell, J., Blaisdell, A. P., and Schlinger, B. A. (2017). Across sex and age: learning and memory and patterns of avian hippocampal gene expression. Behav. Neurosci. 131:483. doi: 10.1037/ bne0000222

Koss, W. A., and Frick, K. M. (2016). Sex differences in hippocampal function. J. Neurosci. Res. 95, 539-562. doi: 10.1002/jnr.23864

Kotrschal, A., Lievens, E. J., Dahlbom, J., Bundsen, A., Semenova, S., Sundvik, M., et al. (2014). Artificial selection on relative brain size reveals a positive genetic correlation between brain size and proactive personality in the guppy. Evolution 68, 1139-1149. doi: 10.1111/evo.12341

Kotrschal, A., Räsänen, K., Kristjansson, B. K., Senn, M., and Kolm, N. (2012). Extreme sexual brain size dimorphism in sticklebacks: a consequence of the cognitive challenges of sex and parenting? PLoS One 7:e30055. doi: 10.1371/ journal.pone. 0030055

Kotrschal, A., Rogell, B., Bundsen, A., Svensson, B., Zajitschek, S., Brännström, I., et al. (2013). Artificial selection on relative brain size in the guppy reveals costs and benefits of evolving a larger brain. Curr. Biol. 23, 168-171. doi: 10.1016/j.cub.2012.11.058

Krause, E. T., Krüger, O., Kohlmeier, P., and Caspers, B. A. (2012). Olfactory kin recognition in a songbird. Biol. Lett. 8, 327-329. doi: 10.1098/rsbl.2011.1093

Kurth, F., Gaser, C., and Luders, E. (2020). Development of sex differences in the human brain. Cogn. Neurosci 12, 155-162.

Laland, K. N., and Reader, S. M. (1999). Foraging innovation in the guppy. Anim. Behav. 57, 331-340. doi: 10.1006/anbe.1998.0967

Landin, J., Hovey, D., Xu, B., Lagman, D., Zettergren, A., Larhammar, D., et al. (2020). Oxytocin receptors regulate social preference in zebrafish. Sci. Rep. 10:5435. 
Lenz, K. M., and McCarthy, M. M. (2010). Organized for sex-steroid hormones and the developing hypothalamus. Eur. J. Neurosci. 32, 2096-2104. doi: 10.1111/j. 1460-9568.2010.07511.x

Lerch, J. P., Yiu, A. P., Martinez-Canabal, A., Pekar, T., Bohbot, V. D., Frankland, P. W., et al. (2011). Maze training in mice induces MRI-detectable brain shape changes specific to the type of learning. Neuroimage 54, 2086-2095. doi: 10. 1016/j.neuroimage.2010.09.086

Lieshoff, C., Große-Ophoff, J., and Bischof, H. J. (2004). Sexual imprinting leads to lateralized and non-lateralized expression of the immediate early gene zenk in the zebra finch brain. Behav. Brain Res. 148, 145-155. doi: 10.1016/s01664328(03)00189-x

Loke, H., Harley, V., and Lee, J. (2015). Biological factors underlying sex differences in neurological disorders. Int. J. Biochem. Cell Biol. 65, 139-150. doi: 10.1016/j. biocel.2015.05.024

Lucon-Xiccato, T., and Bisazza, A. (2014). Discrimination reversal learning reveals greater female behavioural flexibility in guppies. Biol. Lett. 10:20140206. doi: 10.1098/rsbl.2014.0206

Lucon-Xiccato, T., and Bisazza, A. (2016). Male and female guppies differ in speed but not in accuracy in visual discrimination learning. Anim. Cogn. 19, 733-744. doi: 10.1007/s10071-016-0969-2

Lucon-Xiccato, T., and Bisazza, A. (2017a). Individual differences in cognition among teleost fishes. Behav. Proc. 141, 184-195. doi: 10.1016/j.beproc.2017.01. 015

Lucon-Xiccato, T., and Bisazza, A. (2017b). Sex differences in spatial abilities and cognitive flexibility in the guppy. Anim. Behav. 123, 53-60. doi: 10.1016/j. anbehav.2016.10.026

Luders, E., and Kurth, F. (2020). Structural differences between male and female brains. Handb. Clin. Neurol. 175, 3-11. doi: 10.1016/b978-0-444-64123-6. 00001- 1

Lynch, K. S., Ramsey, M. E., and Cummings, M. E. (2012). The mate choice brain: comparing gene profiles between female choice and male coercive poeciliids. Genes Brain Behav. 11, 222-229. doi: 10.1111/j.1601-183X.2011.00742.x

Maekawa, F., Tsukahara, S., Kawashima, T., Nohara, K., and Ohki-Hamazaki, H. (2014). The mechanisms underlying sexual differentiation of behavior and physiology in mammals and birds: relative contributions of sex steroids and sex chromosomes. Front. Neurosci. 8:242. doi: 10.3389/fnins.2014.00242

Maguire, E. A., Gadian, D. G., Johnsrude, I. S., Good, C. D., Ashburner, J., Frackowiak, R. S., et al. (2000). Navigation-related structural change in the hippocampi of taxi drivers. Proc. Natl. Acad. Sci. U.S.A. 97, 4398-4403. doi: 10.1073/pnas.070039597

Mamuneas, D., Spence, A. J., Manica, A., and King, A. J. (2015). Bolder stickleback fish make faster decisions, but they are not less accurate. Behav. Ecol. 26, 91-96. doi: 10.1093/beheco/aru160

Manson, J. E. (2008). Prenatal exposure to sex steroid hormones and behavioral/cognitive outcomes. Metabolism 57, S16-S21. doi: 10.1016/j. metabol.2008.07.010

Marhounová, L., Kotrschal, A., Kverková, K., Kolm, N., and Němec, P. (2019). Artificial selection on brain size leads to matching changes in overall number of neurons. Evolution 73, 2003-2012. doi: 10.1111/evo.13805

Marques, J. C., Lackner, S., Félix, R., and Orger, M. B. (2018). Structure of the zebrafish locomotor repertoire revealed with unsupervised behavioral clustering. Curr. Biol. 28, 181-195. doi: 10.1016/j.cub.2017. 12.002

Martinez, L. A., and Petrulis, A. (2013). The medial preoptic area is necessary for sexual odor preference, but not sexual solicitation, in female Syrian hamsters. Horm. Behav. 63, 606-614. doi: 10.1016/j.yhbeh.2013.02.003

Maruska, K. P., Becker, L., Neboori, A., and Fernald, R. D. (2013). Social descent with territory loss causes rapid behavioral, endocrine and transcriptional changes in the brain. J. Exp. Biol. 216, 3656-3666. doi: 10.1242/jeb. 088617

Maruska, K. P., Fernald, R. D., and Canli, T. (2014). Social regulation of gene expression in the African cichlid fish Astatotilapia burtoni. Handb. Mol. Psychol. 52-78.

Mayer, U., Rosa-Salva, O., Lorenzi, E., and Vallortigara, G. (2016). Social predisposition dependent neuronal activity in the intermediate medial mesopallium of domestic chicks (Gallus gallus domesticus). Behav. Brain Res. 310, 93-102. doi: 10.1016/j.bbr.2016.05.019
Mazza, V., Eccard, J. A., Zaccaroni, M., Jacob, J., and Dammhahn, M. (2018). The fast and the flexible: cognitive style drives individual variation in cognition in a small mammal. Anim. Behav. 137, 119-132. doi: 10.1016/j.anbehav.2018.01.011

Mazza, V., Jacob, J., Dammhahn, M., Zaccaroni, M., and Eccard, J. A. (2019). Individual variation in cognitive style reflects foraging and anti-predator strategies in a small mammal. Sci. Rep. 9, 1-9. doi: 10.1038/s41598-019-46582-1

McEwen, B. S., and Milner, T. A. (2017). Understanding the broad influence of sex hormones and sex differences in the brain. J. Neurosci. Res. 95, 24-39. doi: 10.1002/jnr.23809

McIntosh, A. R. (2000). Towards a network theory of cognition. Neural. Netw. 13, 861-870. doi: 10.1016/s0893-6080(00)00059-9

Moreno, A., and Mossio, M. (2015). Biological Autonomy: A Philosophical And Theoretical Enquiry. Berlin: Springer Verlag.

Nowicki, S., Searcy, W. A., and Peters, S. (2002). Brain development, song learning and mate choice in birds: a review and experimental test of the" nutritional stress hypothesis". J. Comp. Physiol. A 188, 1003-1014. doi: 10.1007/s00359002-0361-3

O'Connell, L. A., and Hofmann, H. A. (2011). The vertebrate mesolimbic reward system and social behavior network: a comparative synthesis. J. Comp. Neurol. 519, 3599-3639. doi: 10.1002/cne.22735

O'Connell, L. A., and Hofmann, H. A. (2012). Evolution of a vertebrate social decision-making network. Science 336, 1154-1157. doi: 10.1126/science. 1218889

Paredes, R. G., and Baum, M. J. (1995). Altered sexual partner preference in male ferrets given excitotoxic lesions of the preoptic area/anterior hypothalamus. J. Neurosci. 15, 6619-6630. doi: 10.1523/JNEUROSCI.15-10-06619.1995

Pearce, E., Wlodarski, R., Machin, A., and Dunbar, R. I. (2019). Genetic influences on social relationships: sex differences in the mediating role of personality and social cognition. Adapt. Hum. Behav. Physiol. 5, 331-351. doi: 10.1093/gerona/ glaa247

Petrulis, A. (2013). Chemosignals and hormones in the neural control of mammalian sexual behavior. Front. Neuroendocrinol. 34:255-267. doi: 10.1016/ j.yfrne.2013.07.007

Pfaus, J. G., Kippin, T. E., Coria-Avila, G. A., Gelez, H., Afonso, V. M., Ismail, N., et al. (2012). Who, what, where, when (and maybe even why)? How the experience of sexual reward connects sexual desire, preference, and performance. Arch. Sex Behav. 41, 31-62. doi: 10.1007/s10508-012-9935-5

Phelps, S. M., Rand, A. S., and Ryan, M. J. (2006). A cognitive framework for mate choice and species recognition. Am. Nat. 167, 28-42. doi: 10.1086/498538

Plath, N., Ohana, O., Dammermann, B., Errington, M. L., Schmitz, D., Gross, C., et al. (2006). Arc/Arg3. 1 is essential for the consolidation of synaptic plasticity and memories. Neuron 52, 437-444. doi: 10.1016/j.neuron.2006.08.024

Pollen, A. A., Dobberfuhl, A. P., Scace, J., Igulu, M. M., Renn, S. C., Shumway, C. A., et al. (2007). Environmental complexity and social organization sculpt the brain in Lake Tanganyikan cichlid fish. Brain Behav. Evol. 70, 21-39. doi: $10.1159 / 000101067$

Proverbio, A. M. (2017). Sex differences in social cognition: the case of face processing. J. Neurosci. Res. 95, 222-234. doi: 10.1002/jnr.23817

Proverbio, A. M. (2021). Sex differences in the social brain and in social cognition. J. Neurosci. Res. 1-9. doi: 10.1002/jnr.24787

Quallo, M. M., Price, C. J., Ueno, K., Asamizuya, T., Cheng, K., Lemon, R. N., et al. (2009). Gray and white matter changes associated with tool-use learning in macaque monkeys. Proc. Natl. Acad. Sci. U.S.A. 106, 18379-18384. doi: 10.1073/pnas.0909751106

Ramsey, M. E., Maginnis, T. L., Wong, R. Y., Brock, C., and Cummings, M. E. (2012). Identifying context-specific gene profiles of social, reproductive, and mate preference behavior in a fish species with female mate choice. Front. Neurosci. 6:62. doi: 10.3389/fnins.2012.00062

Ramsey, M. E., Vu, W., and Cummings, M. E. (2014). Testing synaptic plasticity in dynamic mate choice decisions: N-methyl d-aspartate receptor blockade disrupts female preference. Proc. R. Soc. B Biol. Sci. 281:20140047. doi: 10.1098/ rspb.2014.0047

Reader, S. (2003). Innovation and social learning: individual variation and brain evolution. Anim. Biol. 53, 147-158. doi: 10.1163/157075603769700340

Reader, S. M., and Laland, K. N. (2002). Social intelligence, innovation, and enhanced brain size in primates. Proc. Natl. Acad. Sci. U.S.A. 99, 4436-4441. doi: 10.1073/pnas.062041299 
Reader, S. M., and MacDonald, K. (2003). "Environmental variability and primate behavioural flexibility," in Animal Innovation, eds S. M. Reader and K. N. Laland (Oxford: Oxford University Press), 83-116. doi: 10.1093/acprof:oso/ 9780198526223.003.0004

Richerson, P. J., and Boyd, R. (2000). Climate, culture and the evolution of cognition. Evol. Cogn. 329-345.

Ristori, J., Cocchetti, C., Romani, A., Mazzoli, F., Vignozzi, L., Maggi, M., et al. (2020). Brain sex differences related to gender identity development: genes or hormones? Int. J. Mol. Sci. 21:2123. doi: 10.3390/ijms21062123

Robinson, G. E., Fernald, R. D., and Clayton, D. F. (2008). Genes and social behavior. Science 322, 896-900

Rosenthal, G. G., (2017). Mate Choice. Princeton, NJ: Princeton University Press, doi: $10.1515 / 9781400885466$

Rossi, M., Hausmann, A. E., Thurman, T. J., Montgomery, S. H., Papa, R., Jiggins, C. D., et al. (2020). Visual mate preference evolution during butterfly speciation is linked to neural processing genes. Nat. Commun. 11, 1-10. doi: 10.1038/ s41467-020-18609-z

Ruppé, L., Clément, G., Herrel, A., Ballesta, L., Décamps, T., Kéver, L., et al. (2015). Environmental constraints drive the partitioning of the soundscape in fishes. Proc. Natl. Acad. Sci. U.S.A. 112, 6092-6097. doi: 10.1073/pnas.1424667112

Sakuma, Y. (2008). Neural substrates for sexual preference and motivation in the female and male rat. Ann. N. Y. Acad. Sci. 1129, 55-60. doi: 10.1196/annals. 1417.009

Salva, O. R., Mayer, U., and Vallortigara, G. (2015). Roots of a social brain: developmental models of emerging animacy-detection mechanisms. Neurosci. Biobehav. Rev. 50, 150-168. doi: 10.1016/j.neubiorev.2014.12.015

Samuk, K., Iritani, D., and Schluter, D. (2014). Reversed brain size sexual dimorphism accompanies loss of parental care in white sticklebacks. Ecol. Evol. 4, 3236-3243. doi: 10.1002/ece3.1175

Scholz, B., Kultima, K., Mattsson, A., Axelsson, J., Brunström, B., Halldin, K., et al. (2006). Sex-dependent gene expression in early brain development of chicken embryos. BMC Neurosci. 7:1-17. doi: 10.1186/1471-2202-7-12

Scholz, J., Klein, M. C., Behrens, T. E., and Johansen-Berg, H. (2009). Training induces changes in white-matter architecture. Nat. Neurosci. 12, 1370-1371. doi: $10.1038 / \mathrm{nn} .2412$

Shaw, R. C., and Schmelz, M. (2017). Cognitive test batteries in animal cognition research: evaluating the past, present and future of comparative psychometrics. Anim. Cogn. 20, 1003-1018. doi: 10.1007/s10071-017-1135-1

Shettleworth, S. J. (2001). Animal cognition and animal behaviour. Anim. Behav. 61,277-286. doi: 10.1006/anbe.2000.1606

Shettleworth, S. J. (2010). Clever animals and killjoy explanations in comparative psychology. Trends Cogn. Sci. 14, 477-481. doi: 10.1016/j.tics.2010.07.002

Shultz, S., Bradbury, R. B., L Evans, K., Gregory, R. D., and Blackburn, T. M. (2005), Brain size and resource specialization predict long-term population trends in British birds. Proc. R. Soc. B Biol. Sci. 272, 2305-2311. doi: 10.1098/rspb.2005. 3250

Sih, A., and Del Giudice, M. (2012). Linking behavioural syndromes and cognition: a behavioural ecology perspective. Philos. Trans. R. Soc. B 367, 2762-2772. doi: 10.1098/rstb.2012.0216

Skov, M., and Nadal, M. (2020). The nature of beauty: behavior, cognition, and neurobiology. PsyArXiv [Preprint]. doi: 10.31234/osf.io/c5m87

Smith, T. D., Muchlinski, M. N., Bhatnagar, K. P., Durham, E. L., Bonar, C. J., and Burrows, A. M. (2015). The vomeronasal organ of Lemur catta. Am. J. Primatol. 77, 229-238. doi: 10.1002/ajp.22326

Snell-Rood, E., and Snell-Rood, C. (2020). The developmental support hypothesis: adaptive plasticity in neural development in response to cues of social support. Philos. Trans. R. Soc. B 375:20190491. doi: 10.1098/rstb.2019.0491

Sockman, K. W. (2007). Neural orchestration of mate-choice plasticity in songbirds. J. Ornithol. 148, 225-230. doi: 10.1007/s10336-007$0151-3$

Sockman, K. W., and Ball, G. F. (2009). Independent effects of song quality and experience with photostimulation on expression of the immediate, early gene ZENK (EGR-1) in the auditory telencephalon of female European starlings. Dev Neurobiol. 69, 339-349. doi: 10.1002/dneu.20707

Sockman, K. W., and Lyons, S. M. (2017). How song experience affects female mate-choice. male song, and monoaminergic activity in the auditory telencephalon in lincoln's sparrows. Integr. Comp. Biol. 57, 891-901. doi: 10. 1093/icb/icx080
Sockman, K. W., Gentner, T. Q., and Ball, G. F. (2002). Recent experience modulates forebrain gene-expression in response to mate-choice cues in European starlings. Proc. R. Soc. B Biol. Sci. 269, 2479-2485. doi: 10.1098/rspb. 2002.2180

Sol, D. (2009a). "7. The Cognitive-Buffer Hypothesis for the Evolution of Large Brains," in Cognitive ecology II, eds R. Dukas and J. M. Ratcliffe (Chicago: University of Chicago Press), 111-134. doi: 10.1002/ece3.2961

Sol, D. (2009b). Revisiting the cognitive buffer hypothesis for the evolution of large brains. Biol. Lett. 5, 130-133. doi: 10.1098/rsbl.2008.0621

Sol, D., and Lefebvre, L. (2000). Behavioural flexibility predicts invasion success in birds introduced to New Zealand. Oikos 90, 599-605. doi: 10.1034/j.1600-0706. 2000.900317.x

Sol, D., Bacher, S., Reader, S. M., and Lefebvre, L. (2008). Brain size predicts the success of mammal species introduced into novel environments. Am. Nat. 172, S63-S71.

Sol, D., Duncan, R. P., Blackburn, T. M., Cassey, P., and Lefebvre, L. (2005). Big brains, enhanced cognition, and response of birds to novel environments. Proc. Natl. Acad. Sci. U.S.A. 102, 5460-5465. doi: 10.1073/pnas. 0408145102

Sol, D., Sayol, F., Ducatez, S., and Lefebvre, L. (2016). The life-history basis of behavioural innovations. Philos. Trans. R. Soc. Lond. B Biol. Sci. 371:20150187. doi: $10.1098 /$ rstb.2015.0187

Sporns, O. (2010). Networks Of The Brain. Cambridge, MA: MIT press.

Takigami, S., Mori, Y., and Ichikawa, M. (2000). Projection pattern of vomeronasal neurons to the accessory olfactory bulb in goats. Chem. Senses 25, 387-393. doi: 10.1093/chemse/25.4.387

Templeton, J. J., McCracken, B. G., Sher, M., and Mountjoy, D. J. (2014). An eye for beauty: lateralized visual stimulation of courtship behavior and mate preferences in male zebra finches, Taeniopygia guttata. Behav. Proc. 102, 33-39. doi: 10.1016/j.beproc.2013.11.001

Terranova, J. I., Ferris, C. F., and Albers, H. E. (2017). Sex differences in the regulation of offensive aggression and dominance by arginine-vasopressin. Front. Endocrin. 8:308. doi: 10.3389/fendo.2017.00308

Thornton, A. (2008). Social learning about novel foods in young meerkats. Anim. Behav. 76, 1411-1421. doi: 10.1016/j.anbehav.2008.07.007

Thornton, A., and Lukas, D. (2012). Individual variation in cognitive performance: developmental and evolutionary perspectives. Philos. Trans. R. Soc. B Biol. Sci. 367, 2773-2783. doi: 10.1098/rstb.2012.0214

Thornton, A., and McAuliffe, K. (2006). Teaching in wild meerkats. Science 313, 227-229. doi: 10.1126/science.1128727

Thornton, A., and Raihani, N. J. (2010). Identifying teaching in wild animals. Learn. Behav. 38, 297-309. doi: 10.3758/lb.38.3.297

Titulaer, M., van Oers, K., and Naguib, M. (2012). Personality affects learning performance in difficult tasks in a sex-dependent way. Anim. Behav. 83, 723730. doi: 10.1016/j.anbehav.2011.12.020

Toli, E. A., Noreikiene, K., DeFaveri, J., and Merilä, J. (2017). Environmental enrichment, sexual dimorphism, and brain size in sticklebacks. Ecol. Evol. 7, 1691-1698. doi: 10.1002/ece3.2717

Tsao, D. Y., Freiwald, W. A., Tootell, R. B., and Livingstone, M. S. (2006). A cortical region consisting entirely of face-selective cells. Science 311, 670-674. doi: 10.1126/science.1119983

Tsao, D. Y., Moeller, S., and Freiwald, W. A. (2008). Comparing face patch systems in macaques and humans. Proc. Natl. Acad. Sci. U.S.A. 105, 19514-19519. doi: 10.1073/pnas.0809662105

Tunbak, H., Vazquez-Prada, M., Ryan, T. M., Kampff, A. R., and Dreosti, E. (2020). Whole-brain mapping of socially isolated zebrafish reveals that lonely fish are not loners. Elife 9:e55863. doi: 10.7554/eLife.55863

Turano, A., Osborne, B. F., and Schwarz, J. M. (2018). "Sexual differentiation and sex differences in neural development," in Neuroendocrine Regulation of Behavior, eds L. M. Coolen, and D. R. Grattan (Cham: Springer), 69-110. doi: 10.1007/7854_2018_56

Taylor, R. C., Akre, K., Wilczynski, W., and Ryan, M. J. (2019). Behavioral and neural auditory thresholds in a frog. Curr. Zool. 65, 333-341. doi: 10.1093/cz/ zoy089

Vallortigara, G., and Versace, E. (2017). "Laterality at the neural, cognitive, and behavioral levels," in Apa Handbook Of Comparative Psychology: Basic Concepts, Methods, Neural Substrate, And Behavior, Vol. 1, eds J. Call, G. M. Burghardt, I. M. Pepperberg, C. T. Snowdon, and T. Zentall (Washington, DC: American Psychological Association), 557-577. doi: 10.1037/0000011-027 
Van Ruijssevelt, L., Chen, Y., von Eugen, K., Hamaide, J., De Groof, G., Verhoye, M., et al. (2018). FMRI reveals a novel region for evaluating acoustic information for mate choice in a female songbird. Curr. Biol. 28, 711-721. doi: $10.1016 /$ j.cub.2018.01.048

Vedin, V., Eriksson, B., and Berghard, A. (2010). Organization of the chemosensory neuroepithelium of the vomeronasal organ of the Scandinavian moose Alces alces. Brain Res. 1306, 53-61. doi: 10.1016/j.brainres.2009.10.012

Wallace, K. J., Rausch, R. T., Ramsey, M. E., and Cummings, M. E. (2020). Sex differences in cognitive performance and style across domains in mosquitofish (Gambusia affinis). Anim. Cogn 23, 655-669. doi: 10.1007/s10071-020-01367-2

Wang, S. M. T., Ramsey, M. E., and Cummings, M. E. (2014). Plasticity of the mate choice mind: courtship evokes choice-like brain responses in females from a coercive mating system. Genes Brain Behav. 13, 365-375. doi: 10.1111/gbb. 12124

Weitekamp, C. A., and Hofmann, H. A. (2014). Evolutionary themes in the neurobiology of social cognition. Curr. Opin. Neurobiol. 28, 22-27. doi: 10. 1016/j.conb.2014.06.005

Whitney, O., Pfenning, A. R., Howard, J. T., Blatti, C. A., Liu, F., Ward, J. M., et al. (2014). Core and region-enriched networks of behaviorally regulated genes and the singing genome. Science 346:1256780. doi: 10.1126/science.1256780

Wilczynski, W., and Ryan, M. J. (2010). The behavioral neuroscience of anuran social signal processing. Curr. Opin. Neurobiol. 20, 754-763. doi: 10.1016/j. conb.2010.08.021

Wong, R. Y., and Cummings, M. E. (2014). Expression patterns of neuroligin-3 and tyrosine hydroxylase across the brain in mate choice contexts in female swordtails. Brain Behav. Evol. 83, 231-243. doi: 10.1159/000360071

Wong, R. Y., Ramsey, M. E., and Cummings, M. E. (2012). Localizing brain regions associated with female mate preference behavior in a swordtail. PLoS One 7:e50355. doi: 10.1371/journal.pone.0050355

Wood, L. S., Desjardins, J. K., and Fernald, R. D. (2011). Effects of stress and motivation on performing a spatial task. Neurobiol. Learn. Mem. 95, 277-285. doi: $10.1016 /$ j.nlm.2010.12.002

Xiao, J., Kannan, G., Jones-Brando, L., Brannock, C., Krasnova, I. N., Cadet, J. L., et al. (2012). Sex-specific changes in gene expression and behavior induced by chronic Toxoplasma infection in mice. Neuroscience 206, 39-48. doi: 10.1016/ j.neuroscience.2011.12.051

Xu, L., Becker, B., Luo, R., Zheng, X., Zhao, W., Zhang, Q., et al. (2020). Oxytocin amplifies sex differences in human mate choice. Psychoneuroendocrinology 112:104483. doi: 10.1016/j.psyneuen.2019.104483
Yagi, S., and Galea, L. A. (2019). Sex differences in hippocampal cognition and neurogenesis. Neuropsychopharmacology 44, 200-213. doi: 10.1038/s41386018-0208-4

Yagi, S., Chow, C., Lieblich, S. E., and Galea, L. A. (2016). Sex and strategy use matters for pattern separation, adult neurogenesis, and immediate early gene expression in the hippocampus. Hippocampus 26, 87-101. doi: 10.1002/hipo. 22493

Yagi, S., Drewczynski, D., Wainwright, S. R., Barha, C. K., Hershorn, O., and Galea, L. A. (2017). Sex and estrous cycle differences in immediate early gene activation in the hippocampus and the dorsal striatum after the cue competition task. Horm. Behav. 87, 69-79. doi: 10.1016/j.yhbeh.2016.10.019

Zayed, A., Naeger, N. L., Rodriguez-Zas, S. L., and Robinson, G. E. (2012). Common and novel transcriptional routes to behavioral maturation in worker and male honey bees. Genes Brain Behav 11, 253-261. doi: 10.1111/j.1601183X.2011.00750.x

Zhong, J., Liang, M., Akther, S., Higashida, C., Tsuji, T., and Higashida, H. (2014). c-Fos expression in the paternal mouse brain induced by communicative interaction with maternal mates. Mol. Brain 7, 1-11. doi: 10.1186/s13041-0140066-X

Zhuang, J. Y., Xie, J., Li, P., Fan, M., and Bode, S. (2021). Neural profiles of observing acceptance and rejection decisions in human mate choice copying. Neuroimage 233:117929. doi: 10.1016/j.neuroimage.2021.117929

Conflict of Interest: The author declares that the research was conducted in the absence of any commercial or financial relationships that could be construed as a potential conflict of interest.

Publisher's Note: All claims expressed in this article are solely those of the authors and do not necessarily represent those of their affiliated organizations, or those of the publisher, the editors and the reviewers. Any product that may be evaluated in this article, or claim that may be made by its manufacturer, is not guaranteed or endorsed by the publisher.

Copyright (c) 2021 Fuss. This is an open-access article distributed under the terms of the Creative Commons Attribution License (CC BY). The use, distribution or reproduction in other forums is permitted, provided the original author(s) and the copyright owner(s) are credited and that the original publication in this journal is cited, in accordance with accepted academic practice. No use, distribution or reproduction is permitted which does not comply with these terms. 